PNL-10510

$\mathrm{UC}-\mathrm{a}$

940

\title{
Redox Reactions and Foaming in Nuclear Waste Glass Melting
}

\author{
J. L. Ryan
}

August 1995

Prepared for

the U.S. Department of Energy

under Contract DE-AC06-76RLO 1830

Pacific Northwest Laboratory

Richland, Washington 99352

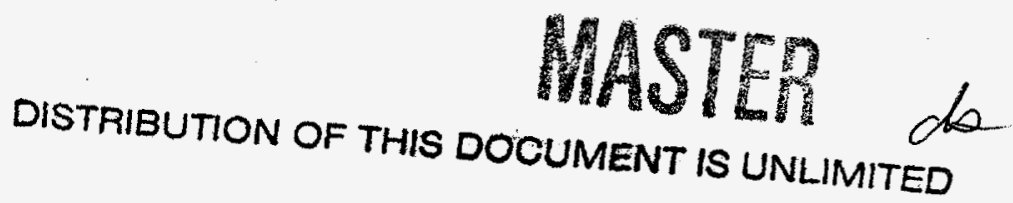





\section{DISCLAIMER}

Portions of this document may be illegible in electronic image products. Images are produced from the best available original document. 


\section{Summary}

Foaming has often been observed in experimental continuous liquid-fed, joule-heated, ceramic melters that produce simulated nuclear waste-containing borosilicate glass. Such foaming, which results in significantly decreased melter throughput rates, has been attributed to the release of $\mathrm{O}_{2}$ gas resulting from the decomposition of higher valency metal oxides to lower valency oxides. It has been claimed that this foaming can best be controlled by adding reducing agents to the melter feed. In particular, the use of formic acid has been proposed to 1) acidify the aqueous waste stream, thereby dissolving some of the hydrous oxides and improving feed rheology, and 2) act as a reducing agent to control foaming.

This document, prepared at Pacific Northwest Laboratory, reviews studies of nuclear waste glass foaming and the effects of reducing agents, particularly formic acid, on such foaming. It reviews the redox chemistry of many of the potential oxidizing and reducing species in or added to the glass-melter feed with the objective of predicting some of the chemistry that occurs in the cold cap and the glass melt as they might affect the foaming phenomenon. The review is not exhaustive since the literature search was limited by the complexity of the subject, and unknown effects on the chemistry, including various unknown catalytic effects, will certainly be important in such complex mixtures.

Based on this review, little is actually known about the causes of or best remedies for foaming in the nuclear waste glass melters. The actual temperature regime (cold cap ${ }^{(a)}$ plus melt) in the melter that is most important to the actual melter foaming is unknown. Workers have made widely different implicit assumptions in this regard. No evidence was found that adequate testing of proposed foaming remedies with well designed control experiments has been conducted in the glass melters.

There is significant evidence based on run experience that, in the absence of added reductants, acidic feeds do not foam nearly as badly as alkaline feeds. Although alkaline feeds promote formation of higher oxidation state metal species in the cold cap, it is far from clear that easier formation of higher oxidation state metals causes the apparent greater foaming with alkaline feeds. The problem is that no run data were found in which only acidity or alkalinity were the significant variables.

Based on the results of this review, there is strong question whether the varying degree of melter foaming is caused by different extents of decomposition of higher oxidation state metal oxides releasing $\mathrm{O}_{2}$, and whether this foaming can, therefore, be best controlled by adding reductants. This concept, while somewhat reasonable, must be proven with carefully designed experiments having virtually identical feeds with and without reductants in adequate quantity. These experiments must also compare other factors such as feed acidity-alkalinity with other variables held constant. Available laboratory data on the effect of reductants do not, for one reason or another, prove their benefit. It appears quite possible that simple acidification of the waste slurry with nitric acid might result in a far better and more predictable solution to the foaming problem than the addition of reductants.

(a) A cold-cap is the unmelted solid or semi-solid material which forms on top of the molten glass in a melter as a result of feeding an aqueous slurry of glass precursors. 
Formic acid has been the most widely recommended reductant for the control of nuclear waste glass foaming. However, formic acid appears to be inefficient and unpredictable as a reductant in the cold cap for the following reasons: Formic acid and its salts follow multiple decomposition routes in the aqueous feed and in the cold cap, respectively. The decomposition temperature of the salts is low relative to their reaction temperature with nitrate and nitrite. This low-temperature decomposition produces reducing gases, which will be lost to an unpredictable degree before reacting with oxidants in the cold cap. Other organic reductants, including other organic acids, may be somewhat more predictable because of higher decomposition temperatures, but none are likely to react stoichiometrically because of their decomposition to reducing gases which may be lost before they can react with the oxidants. 


\section{Contents}

Summary $\ldots \ldots \ldots \ldots \ldots \ldots \ldots \ldots \ldots \ldots \ldots \ldots \ldots \ldots \ldots \ldots \ldots \ldots$

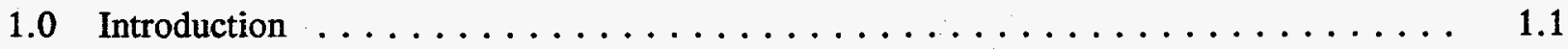

2.0 Effect of Major Feed Variables on Glass Melter Redox Reactions . . . . . . . . . . 2.1

2.1 Oxidants in Melter Feed or Formed in Cold Cap . . . . . . . . . . . 2.4

2.1 .1 Manganese $\ldots \ldots \ldots \ldots \ldots \ldots \ldots \ldots \ldots \ldots \ldots \ldots \ldots \ldots$

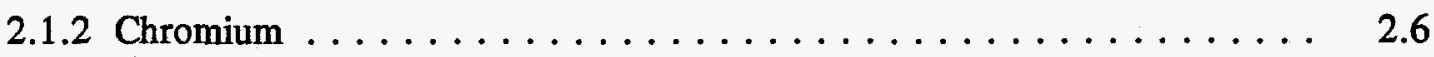

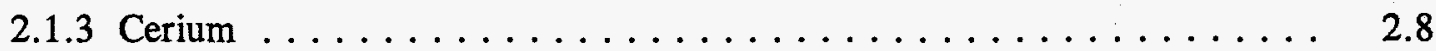

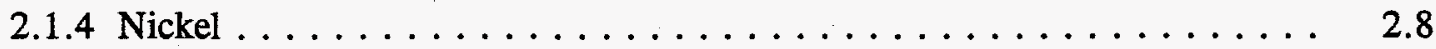

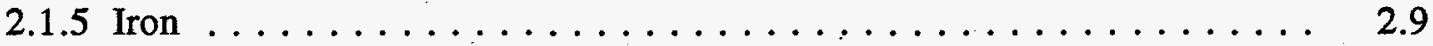

2.1.6 Sodium Nitrate and Sodium Nitrite $\ldots \ldots \ldots \ldots \ldots \ldots \ldots \ldots$

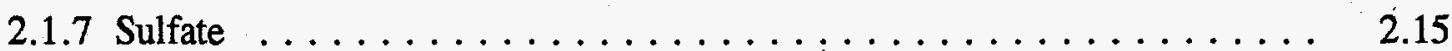

2.2 Reducing Agents Present in or Added to Melter Feed . . . . . . . . . 2.16

2.2 .1 Formic Acid and Formates $\ldots \ldots \ldots \ldots \ldots \ldots \ldots \ldots \ldots \ldots \ldots \ldots$

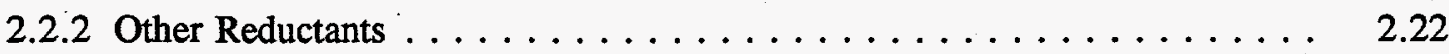

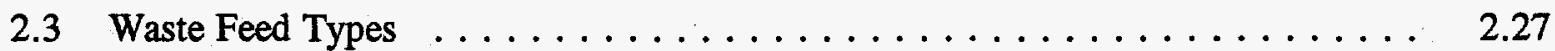

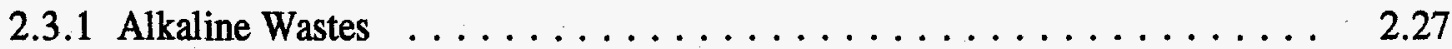

2.3 .2 Acidic Wastes . . . . . . . . . . . . . . . . . . 2.29

2.3 .3 Acidified Reduced Waste $\ldots \ldots \ldots \ldots \ldots \ldots \ldots \ldots \ldots \ldots \ldots \ldots$

2.3.4 Alkaline Reduced Wastes . . . . . . . . . . . . . 2.33

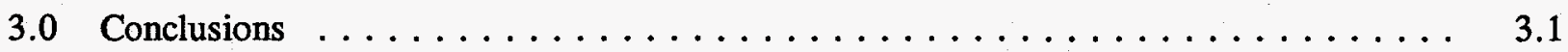

4.0 References $\ldots \ldots \ldots \ldots \ldots \ldots \ldots \ldots \ldots \ldots \ldots \ldots \ldots \ldots \ldots \ldots \ldots$ 



\subsection{Introduction}

This document was prepared by Pacific Northwest Laboratory (PNL) ${ }^{(a)}$ and is an attempt to analyze and estimate the effects of feed composition variables and reducing agent variables on the expected chemistry of reactions occurring in the cold cap and in the glass melt in the nuclear waste glass slurry-fed, joule-heated melters as they might affect foaming during the glass-making process. Numerous redox reactions of waste glass components and potential feed additives, and the effects of other feed variables on these reactions are reviewed with regard to their potential effect on glass foaming. A major emphasis of this report is to examine the potential positive or negative aspects of adjusting feed with formic acid as opposed to other feed modification techniques including but not limited to use of other reducing agents. Feed modification techniques other than the use of reductants that should influence foaming behavior include control of glass melter feed $\mathrm{pH}$ through use of nitric acid. They also include partial replacement of sodium salts by lithium salts. This latter action apparently lowers glass viscosity and raises surface tension (Bates and Bowen 1987, pp. 5.8-5.12;(b) Piepel et al. 1993; Paul 1982, pp. 87-88). This replacement should decrease foaming by decreasing foam stability. A companion report ${ }^{(\mathfrak{c})}$ compares the results of experimental studies with the expected chemistry described herein.

Since this waste glass melting process is a very complex, multicomponent system with rapidly changing temperature across the cold cap where both equilibria and kinetics may be important, this review is neither exact nor complete. Much of the information presented will be based on reactions in much simpler systems. Hopefully, the relative effects of changing various feed variables can be better understood and the directions for further research can be defined.

Foaming of glass often occurs during the production of borosilicate waste glass from simulated alkaline wastes in slurry-fed, joule-heated melters. These wastes contain large amounts of $\mathrm{Fe}$ and nitrate/nitrite and smaller amounts of $\mathrm{Cr}, \mathrm{Mn}, \mathrm{Ce}$, and $\mathrm{SO}_{4}^{2-}$. At glassmaking temperatures or below, these components can act as oxidizing agents that liberate oxygen. As temperature increases, the stability of higher oxidation states of multivalent elements decreases. This slow decomposition of higher oxidation state species can produce gases below, at, or above the desired glass formation temperature. As an example, pure $\mathrm{NaNO}_{3}$ releases $\mathrm{O}_{2}$ to form $\mathrm{NaNO}_{2}$ in the temperature range $500^{\circ}$ to $700^{\circ} \mathrm{C}$ (Gordon and Campbell 1955; Bond and Jacobs 1966; Freeman 1956; Sirotkin 1959; Burger et al. 1973). In commercial Mn-containing glasses, small temperature increases in the glass-forming region can be expected to release $\mathrm{O}_{2}$ and thereby cause foaming (Volf 1984, p. 342). Decomposition

(a) Pacific Northwest Laboratory is operated for the U.S. Department of Energy by Battelle Memorial Institute under Contract DE-AC06-76RLO 1830.

(b) Bates, S. O., and W. M. Bowen. 1987. Interim Milestone HWVP-86-V1122C, Report on Composition Variability Testing Conducted for the Hanford Waste Vitrification Program. Letter Report for Rockwell Hanford Operations and the U.S. Department of Energy, Pacific Northwest Laboratory, Richland, Washington.

(c) Smith, P. A., and J. D. Vienna. 1994. NCAW Feed Chemistry: Effect of Starting Chemistry on Melter Offgas and Iron Redox, Letter Report PVTD-C94-03.02K. 
of $\mathrm{Fe}$ (III) oxide to $\mathrm{Fe}$ (II) oxide in $2 \%$ to $3 \% \mathrm{Fe}_{2} \mathrm{O}_{3}$ glass melts can produce vigorous boiling in tanks at $1300^{\circ} \mathrm{C}$ and above (Volf 1984, pp. 349 and 356).

It is well recognized in commercial glassmaking, that various higher oxidation state species (including $\mathrm{SO}_{4}^{2-}$ and higher oxidation states of $\mathrm{Fe}, \mathrm{Cr}, \mathrm{Ce}$, and $\mathrm{Mn}$ ) can decompose in glass to produce oxygen bubbles in glass melts (Volf 1984; Weyl 1951; Paul 1982). Different oxidants produce $\mathrm{O}_{2}$ at different temperatures and a mixture of those shown should yield $\mathrm{O}_{2}$ up to over $1500^{\circ} \mathrm{C}$. Of course, other gases are also released in the process of forming the glass, including water vapor, $\mathrm{CO}_{2}$ if carbonates are feed components, and $\mathrm{N}_{2}$ or $\mathrm{NO}_{\mathrm{x}}$ if nitrites or nitrates are present. Depending on the rate of temperature change and other variables, this gas may be released slowly or rapidly (boiling). Whether the released gases produce glass foam depends not only on the rate at which gas is formed, but also on the glass viscosity and surface tension of the glass at the temperature of gas release (Paul 1982, pp. 78 and 87). The stability of foams should also be related to the gas bubble size, which is related to the particulate size of solids on which the gas bubble nucleates or is formed in the liquidsolid glass forming reaction (Volf 1984, pp. 147-151). Various foaming "depressors" have been used to break the foams produced in the $\mathrm{SiO}_{2}$ reaction with carbonates in commercial glassmaking, and Volf (1984, p. 148) noted that, "Sodium sulfate is the most effective foam remover in glass melts." The sodium sulfate apparently accomplishes this largely by its effect on surface tension. On the other hand, sulfate in glass can decompose slowly to produce $\mathrm{O}_{2}$ and prevent the conversion of $\mathrm{Fe}$ (III) to $\mathrm{Fe}$ (II) until temperatures become quite high $\left(1500^{\circ} \mathrm{C}\right)$, at which point sulfate decomposition rapidly produces bubbles (Volf 1984, p. 355).

Significant foaming has occurred in joule-heated, liquid-fed ceramic melters while producing nuclear waste glasses. Apparently, the foaming often occurs as a runaway reaction when the melter power level is increased. This foaming often completely overruns the cold cap (the solid or semisolid zone that is the transition between the aqueous slurry feed and the liquid glass) (R. D. Dierks, PNL, personal communication; J. Perez, PNL, personal communication). This foaming has been described (R. D. Dierks, PNL, personal communication) as having the appearance of boiling oatmeal with foam completely overflowing the cold cap until the cold cap disappears. This rapid foaming necessitates that melter power and feed rate be reduced for recovery, which results in a decreased glass production rate.

Foaming has been proposed to result from oxygen release caused by the decrease in higher oxidation state stability of various multivalent elements (Blair and Lukacs 1980; Goldman and Brite 1986; Goldman, Brite, and Richey 1986; Lucktong and Hrma 1988; Goldman 1986). Such a conclusion is certainly logical because of the significant amount of evidence for foaming produced by such mechanisms in commercial glasses. However, a critical evaluation reveals that all of these papers and the work on which they are based are at least to some extent flawed. Although the general conclusions may or may not be basically correct, the authors do not conclusively prove their hypotheses. Thus, the fact that adding $\mathrm{Mn}_{3} \mathrm{O}_{4}$ to molten borosilicate glass at $1150^{\circ} \mathrm{C}$ causes foaming (Lucktong and Hrma 1988), while indicating that the reaction:

$$
\mathrm{Mn}(\mathrm{III})+1 / 2 \mathrm{O}^{2-} \rightarrow \mathrm{Mn}(\mathrm{II})+1 / 4 \mathrm{O}_{2}
$$

occurs in borosilicate melts at $1150^{\circ} \mathrm{C}$, does not prove that $\mathrm{Mn}$ (III), or $\mathrm{Mn}$ at all, is the chief cause of foaming problems in liquid-fed ceramic melters. Also, laboratory experiments were conducted using small crucibles of glass batches (Blair and Lukacs 1980). The observation that foaming was suppos- 
edly lessened by slightly more than the demonstrated experimental scatter by the addition of all the Fe and $\mathrm{Mn}$ as $\mathrm{FeO}$ and $\mathrm{MnO}$ instead of as $\mathrm{Fe}(\mathrm{III})$ and $\mathrm{MnO}_{2}$ does not prove that higher oxidation state $\mathrm{Fe}$ and $\mathrm{Mn}$ species produce the foaming observed in the liquid-fed melters. This is because $\mathrm{FeO}$ and $\mathrm{MnO}$ are expected to readily oxidize during heat-up to glass forming temperature (certainly in laboratory furnaces). In fact, pure $\mathrm{FeO}$ is a pyrophoric material and $\mathrm{MnO}$ takes up $\mathrm{O}_{2}$ slowly even at room temperature (Bailar et al. 1973c, pp. 1008-1009, 799). Volf (1984, pp. 344-345) noted that in commercial glassmaking of $\mathrm{Mn}-\mathrm{Cr}$-containing glasses, the oxidation states in which the $\mathrm{Mn}$ and $\mathrm{Cr}$ are added have little effect because of oxidation in the furnace atmosphere below glass-forming temperatures. Volf also indicated $(1984$, p. 352) that in Fe-Mn glasses," ... the forms in which both Mn and Fe are introduced into the glass are therefore of no consequence." Weyl (1951, pp. 127-128) noted that MnO is oxidized to $\mathrm{Mn}_{3} \mathrm{O}_{4}$ between $200^{\circ}$ and $400^{\circ} \mathrm{C}$ and, " ... that even in the absence of oxidizing agents, higher oxides of manganese can be formed in the glass batch when oxygen is present in the furnace atmosphere."

Because decomposition of some higher-valent oxides to release oxygen can produce foaming in molten glass, it was logical to study and use reducing agents to avoid these higher oxidation state species during waste glass production (Blair and Lukacs 1980; Goldman and Brite 1986; Goldman, Brite, and Richey 1986; Lucktong and Hrma 1988; Goldman 1986). The use of reducing agents (carbon, organic compounds, aluminum, silicon, etc.) or oxidizing agents (typically alkali nitrates or various metal or nonmetal oxides) to control the redox level of glasses is a well known practice, though these procedures are almost always applied to commercial glass to control color rather than to solve foaming problems. The use of appropriate amounts of reducing or oxidizing agents is also well established to control the amount of metallic lead precipitated in fire assaying slags (typically lead glasses) in gold and other precious metal analyses.

The use of formic acid to treat the aqueous feed for liquid-fed ceramic melters producing borosilicate waste glass was developed at Savannah River Laboratory (SRL) (Bickford et al. 1992; Bickford, Diemer, and Iverson 1986; Ritter, Zamecnik, and Hsu 1992). The original purpose of this addition was to reduce $\mathrm{Hg}$ compounds or ions to the metallic state $\left(\mathrm{Hg}^{\circ}\right)$ for physical removal from waste slurry (Bickford et al. 1992). Formic acid (as well as formaldehyde, sucrose, and ethanol) had previously been studied or used to partially denitrate acidic aqueous nitrate solutions (typically waste streams) (Cecille and Halaszovich 1986). This aqueous phase denitration never completely destroys the last of the nitrate because the reaction slows as acidity drops. Presumably because formic acid dissolves part of the hydrous oxides in the nuclear waste glass aqueous feed slurry, improved feed slurry rheology is reportedly a secondary benefit of using formic acid in feed slurry pretreatment (Bickford, Diemer, and Iverson 1986; Ritter, Zamecnik, and Hsu 1992). This improvement in feed rheology aids the pumpability of the aqueous melter feed. Adding nitric acid would also dissolve hydrous oxides, and it should provide as good or better improvement in feed rheology than formic acid.

Use of reducing agents in the feed to liquid-fed, joule-heated nuclear waste glass melters has been presumed to improve the glass foaming problem, and feed compositions containing formic acid (SRL flowsheet for $\mathrm{Hg}$ removal) have supposedly shown improved performance with regard to foaming (Goldman, Brite, and Richey 1986; Bickford, Hrma, and Bowen 1990). No actual data to support this benefit of formic acid has been found. In discussing the chemistry of producing Fe-containing glasses, Volf $(1984$, p. 355$)$ stated, "When melting under reducing conditions, the difference between the effects of various organic substances (coal, coke, graphite) and the effects of powdered metals (aluminum or silicon) is very small." But remember that Volf's objective is to control the redox state of the final glass produced and not to control the degree of foaming during glass manufacture. 
Note that production of essentially all commercial glasses and certainly nuclear waste glasses with normally used feedstocks will produce significant amounts of gases. Also, recognize that addition of carbonaceous reducing agents (various forms of carbon and organic compounds) to nuclear waste glass feeds containing oxidants such as nitrates will normally increase rather than decrease the total quantity of gases produced. These reducing agents, then, can reduce foaming only by changing the conditions under which the gases are released rather than by decreasing gas quantity. These conditions are the temperature of release and the physical properties (such as viscosity and surface tension) of the glassforming mix, including the inhomogeneous liquid (fluxes) and solid mixtures in the cold cap and the glass up to final homogenization and maximum glass temperature in the melter.

With many commercial glasses using alkali and alkaline earth carbonates as major feedstock components, most of the released gas is $\mathrm{CO}_{2}$, and this is released during reaction of alkali and alkaline earth carbonates with silica. Since the viscosity of glass increases markedly with $\mathrm{SiO}_{2}$ content (Paul 1982, pp. 76-85), it can be expected that most of this gas will be released when the acidic components $\left(\mathrm{SiO}_{2}, \mathrm{~B}_{2} \mathrm{O}_{3}\right.$, etc.) react with the carbonates to form $\mathrm{M}_{2} \mathrm{O}$ - and $\mathrm{MO}$-rich silicates. After these have formed, the further dissolution of silica raises the liquid content and the viscosity and if further gas is released, foaming is more likely. This is particularly true in the acidic borosilicate commercial glasses (such as Pyrex) where reaction between $\mathrm{Na}_{2} \mathrm{CO}_{3}$ and $\mathrm{H}_{3} \mathrm{BO}_{3}$ releases all the $\mathrm{CO}_{2}$ in the $500^{\circ}$ to $600^{\circ} \mathrm{C}$ range at relatively low melt viscosity. Only at higher temperatures does $\mathrm{SiO}_{2}$ (sand) simply dissolve in the alkali borate melt without entering into a gas producing chemical reaction (Volf 1984, p. 194). This means that the $\mathrm{CO}_{2}$ is released before most of the silica has entered the melt and raised the viscosity. Actually the effect of $\mathrm{B}_{2} \mathrm{O}_{3}$ is more complex since only $0.75 \% \mathrm{~B}_{2} \mathrm{O}_{3}$ accelerates melting of alkali-lime-silica glasses and decreases the foaming that occurs with some of these glasses on $\mathrm{SiO}_{2}$ dissolution (Volf 1984, pp. 194-195). This has been attributed to the low melting fluxes obtained when using hydrated boric acid or borates, as well as to the decrease in glass surface tension produced by even small amounts of boron.

With nuclear waste glass, there may or may not be carbonate in the glass feed and the principal gases other than $\mathrm{CO}_{2}$ will be $\mathrm{H}_{2} \mathrm{O}, \mathrm{O}_{2}$, and $\mathrm{N}_{2}$ or $\mathrm{NO}_{\mathrm{x}}$. Some of the $\mathrm{O}_{2}$ and the $\mathrm{N}_{2}$ or $\mathrm{NO}_{\mathrm{x}}$ originate from nitrates and nitrites, and the remaining $\mathrm{O}_{2}$ results from decomposition of oxides of elements initially in higher oxidation states to lower oxidation states. Carbon dioxide will be a significant component of the melter off gas if the melter feed contains carbonate or organic compounds or other carbon sources either present in the waste or added to the melter feed. Not only should the presence or absence of reducing agents change the temperatures at which these gases (or those resulting from reactions with the reductants) are released, but other changes in the feed composition and the nature of the reductant can affect not only which gases are formed but also the temperature ranges in which they are formed.

These other feed changes include, as an example, the form in which elements such as boron are present in the feed mix (frit versus boric acid or borates). As noted above, boric acid reacts with $\mathrm{Na}_{2} \mathrm{CO}_{3}$ at only $500^{\circ}$ to $600^{\circ} \mathrm{C}$. With acidic feeds, boric acid should be available in the feed whether added as such or as borates, but would be if boron was added along with silica as a frit only if adequate time was allowed for nitric acid to attack the frit. Acidic feeds would not contain carbonates, but if organics were present, would form carbonate below $500^{\circ} \mathrm{C}$. 
It should be emphasized that the use of carbon-containing reducing agents to react with nitrate and nitrite at temperatures below their normal thermal decomposition temperatures will not only increase the total gas to be evolved but will also convert the alkali metal nitrates and nitrates to carbonates as temperature is raised. With nuclear waste glasses of the compositions anticipated, the alkali metal-toboron-to-silica ratio is such that the lower temperature reaction of boric acid with $\mathrm{Na}_{2} \mathrm{CO}_{3}$ will by no means consume all the carbonate, and $\mathrm{CO}_{2}$ will be released as $\mathrm{SiO}_{2}$ or frit is dissolved producing viscous glass $\left(\sim 600^{\circ}\right.$ to $\left.800^{\circ} \mathrm{C}\right)$. Thus, whether a reductant is used or not, considerable gas release must be occurring in this material in the temperature range where glass compounds are actually forming and exhibiting high viscosity.

Whether use of reducing agents to prevent melter foaming problems is appropriate depends on the temperature regime in which the foam is produced and this is apparently not known. Thus, if melter foaming is the result of gas release in the lower temperature, $<850^{\circ} \mathrm{C}$, regime (where high glass viscosity is expected), $\mathrm{CO}_{2}$ release from reduced mixes may be fully adequate to produce foaming. If it is due to gas release at $>1000^{\circ} \mathrm{C}$ (where much lower melt viscosity and foam stability would be expected and where most gases other than $\mathrm{O}_{2}$ have already been released), effective reductants might be an appropriate remedy. 


\subsection{Effect of Major Feed Variables on Glass Melter Redox Reactions}

Several major classes of nuclear waste feed must be defined to better understand the nature of reactions occurring in the nuclear waste glass formation process. Early work on borosilicate nuclear waste glasses concentrated principally on waste produced by processing irradiated commercial power reactor fuel. These wastes result from reprocessing with minimal inorganic additives and are stored acidic. These strongly acidic wastes had a very low alkali nitrate-to-fission product (FP) nitrate ratio. Since addition of nonvolatile components was minimal during fuels reprocessing, these wastes were concentrated considerably by evaporation, and the alkali nitrate content on a concentration basis might be either low or high. For the purposes of discussing the chemistry that occurs during glassmaking, these wastes are designated as acidic, low alkali nitrate wastes or acidic, high alkali nitrate wastes.

Wastes stored at the Hanford Site, at Savannah River Plant, and at the West Valley Plant have been neutralized with $\mathrm{NaOH}$, thereby greatly increasing the alkali nitrate (and through radiolysis nitrite) content of the waste. Although sludge washing will remove significant amounts of $\mathrm{NaNO}_{3}$ and $\mathrm{NaNO}_{2}$, current plans for sludge washing will still leave $\mathrm{NaNO}_{3}+\mathrm{NaNO}_{2}$ as the major sludge components. For Hanford neutralized current acid waste (NCAW), this amounts to about $0.55 \mathrm{M}$ $\mathrm{NaNO}_{3}+\mathrm{NaNO}_{2}$ (assuming a water content yielding $125 \mathrm{~g}$ nonvolatile oxides/L) in the feed to the vitrification plant. ${ }^{(a)}$ If such wastes are again acidified by the addition of nitric acid (as currently planned for West Valley wastes), many of the metal hydrous oxides, carbonates, and hydroxides will be reconverted to nitrates; this waste will be referred to here as an acidic, high alkali nitrate waste. Alkaline wastes that are not acidified will be referred to here simply as alkaline wastes and are always expected to be high in alkali nitrate relative to the acidic, low alkali nitrate wastes defined in the paragraph above. Hanford, Savannah River, and West Valley wastes without acid treatment are alkaline wastes, but West Valley waste has low free hydroxide, most of the alkalinity being carbonate or bicarbonate. Two categories of reduced wastes are defined here for purposes of understanding differences in cold cap and glassmaking chemistry. These are acidified reduced waste and alkaline reduced waste. Included in the former is formated waste as well as waste acidified with nitric acid and containing a variety of possible reducing agents.

The reason for defining these general categories of waste feeds for liquid-fed ceramic melters is to attempt to show the difference in possible chemistry occurring in the aqueous slurry preparation, in the cold cap, and in the final glass melt for these waste categories. Goldman, Brite, and Richey (1986) presented evidence, based on melter run experience, that simulated alkaline West Valley waste caused worse melter foaming than other waste feeds that were studied, and that simulated acidified West Valley waste produced significantly less but still serious melter foaming. Simulated West Valley waste that had first been calcined produced significantly less melter foaming than either the alkaline or acidified waste. Although calcining temperature and conditions were not stated, it is presumed that

(a) Smith, R. A. 1991. Revision of Pretreated Neutralized Current Acid Waste Composition for FY 1991 Pilot Testing. Westinghouse Hanford Company letter to Mr. J. M. Creer, January 21, 1991, Correspondence No. 9150110. 
considerable decomposition of nitrates, some decomposition of nitrites, loss of most water, and conversion of free hydroxide to carbonate (because of exposure to $\mathrm{CO}_{2}$ in air) occurred. The Savannah River wastes, which had been made with formate compounds present and were presumably acidic due to formic acid addition, produced very little melter foaming.

Goldman, Brite, and Richey (1986) showed Hanford current acid waste (CAW) as the least foaming of the glasses they studied, followed by the reduced Savannah River glasses. On the other hand, they showed that NCAW caused rather severe foaming. Unfortunately, Goldman, Brite, and Richey (1986) did not provide detailed feed composition (in particular nitrate, nitrite, hydroxide, and other basic components used to make the glasses they studied). Presumably their Hanford CAW feed would be acidic. It would have a lower alkali and alkaline earth nitrate content than Hanford NCAW feed if the feed consists of the entire simulated CAW simply neutralized by $\mathrm{NaOH}$. Current plans, however, are to vitrify only the washed sludge from NCAW and this could have a much lower alkali nitrate content. Indeed, for the present purpose, it is more important to know the actual composition of the glassmaking feeds used in this work than whether they exactly simulate the real waste that will actually be processed.

Elliot (M. L. Elliot, PNL, personal communication) is preparing a data review of glass melter runs at PNL for the period from mid-1981 to mid-1988. His database summarizes data for 45 melter runs, only two of which (run numbers PSCM-11 and PSCM-17) used simulated Hanford feeds without added reductants. Goldman, Brite, and Richey (1986) stated that the Hanford and West Valley glasses they studied "... were processed under highly oxidizing conditions in which reducing compounds were excluded from the starting materials entering the melter." It can then be assumed that these two melter runs are the source of the Hanford glasses studied by Goldman, Brite, and Richey (1986).

Examination of the input records to Elliott's database indicates run PSCM-17 was designed to simulate acidic CAW, and run PSCM-11 was designed to simulate washed (alkaline) NCAW sludge. These records indicate that PSCM-17 was definitely the source of the CAW glasses studied by Goldman et al. This feed was made up as $1.1 \mathrm{M} \mathrm{HNO}_{3}$, and after correcting for acid consumption in converting added salts of weak acids to the weak acids, would have been at least $0.5 \mathrm{M}$ in $\mathrm{HNO}_{3}$. The feed was also $6.7 \underline{\mathrm{M}}$ in $\mathrm{NO}_{3}^{-}$by makeup (6.3 $\underline{\mathrm{M}}$ by analysis), with about $2 \underline{\mathrm{M}}$ alkali nitrates. Because PSCM-11 was a feed in which most of the alkali metal content as well as the boron was added in frit, and metals like $\mathrm{Fe}$ and $\mathrm{Al}$ were added mostly as hydroxides or hydrous oxides (some $\mathrm{NaAlO}_{2}$ was also added), this feed had a small excess of base (no alkali hydroxide addition is shown). The total melter feed nitrate content was apparently only $0.0257 \underline{\mathrm{M}}$, which is sufficient to oxidize $\mathrm{Cr}, \mathrm{Mn}$, and $\mathrm{Ce}$ to their higher oxidation states.

It is interesting that the simulated NCAW (PSCM-11) foamed badly in the melter, whereas simulated CAW (PSCM-17) did not foam. The nonfoaming CAW feed had 260-fold more nitrate (345-fold more alkali nitrate) in the feed and must have, of necessity, produced much more gas (not including $\mathrm{H}_{2} \mathrm{O}$ vapor) than PSCM-11. Besides $\mathrm{pH}$ and nitrate content, the next most obvious difference between the two feeds was about two-fold higher Fe and $\mathrm{Mn}$ content and about three-fold higher $\mathrm{Ce}$ content in the NCAW feed (Cr was about the same in the two feeds). PSCM-11 was compounded using a frit, whereas PSCM-17 used added glass formers (many as nitrates). Other composition differences include somewhat less lithium in PSCM-11 than in PSCM-17, and lithium lowers viscosity and raises surface tension. When the total potential equivalents of oxidized $\mathrm{Cr}, \mathrm{Mn}$, and $\mathrm{Ce}$ are compared to the literature values of Goldman, Brite, and Richey (1986, Figure 4), the two most oxidized samples of each glass both have $45 \pm 2 \%$ of the possible equivalents (mostly $\mathrm{Cr}$ ) of these elements as $\mathrm{Cr}$ (VI), Mn(III), 
and $\mathrm{Ce}^{4+}$. This extent of oxidation is close to that which would be predicted for this combination of metal ions from the Schreiber et al. (1984) thermodynamic data and the measured reboil pressures (discussed below). This would tend to indicate that these glass samples were near equilibrium at $1150^{\circ} \mathrm{C}$.

Goldman, Brite, and Richey (1986) measured total reboil pressures (the pressure at which vigorous bubbling occurred at $1150^{\circ} \mathrm{C}$ ) of these various glasses samples after they were formed and noted a general positive correlation between the reboil pressure and foaming experience in the melters. Although this correlation certainly appeared to be real, it cannot be considered quantitative since the range in values of reboil pressure for a given waste feed are up to almost half the total range for all these glasses. Actually, there is no fundamental reason to expect that reboil pressures (all below one atmosphere) of glasses already made at about $1150^{\circ} \mathrm{C}$ should be a good measure of the tendency to foam during the glass-forming process. The reboil pressure is a measure of the vapor pressure of residual dissolved gas remaining after the glass was made and might be expected to be more dependent on the exact temperature and possibly time the glass was held in the melter before sampling. This is strongly supported by the observation cited above that these glass samples appeared to be near equilibrium in oxidized species at $1150^{\circ} \mathrm{C}$. The foaming would be expected to be more dependent on the gas production rate, glass viscosity, and glass surface tension at some undefined temperature below the final maximum glass melt temperature (probably well below $900^{\circ} \mathrm{C}$ ).

If foaming in the melters is simply a matter of shifting the redox equilibrium of a metal oxide couple from one position to another position due to melter power and thus temperature increases, instead of reactions before final glass homogenization, the $\mathrm{O}_{2}$ pressure will be some power function of the oxidized/reduced ratio and the equilibrium constants. On the other hand, the $\mathrm{O}_{2}$ quantity (potential quantity of foam) will also be a function of the total quantity of the oxidized form of the redox couple. The actual quantity of foam produced would then be a function not only of how fast this gas is produced (in turn related, if kinetics are fast, to both the total quantity of oxidant present and to the degree of shift of the equilibrium position), but also of how long the foam bubbles last, which is controlled by melt viscosity and surface tension. Certainly the glass viscosity can be expected to be highest in the region near the cold cap where the temperature is such that the bulk of the $\mathrm{SiO}_{2}$ or frit is dissolving in the melt and the melt is just approaching a homogeneous state (glass is just forming, but the temperature is still far below the maximum melter temperature of $1150^{\circ} \mathrm{C}$ ).

The following subsections discuss the nature of the various chemical redox reactions expected to occur in general and in the various categories of nuclear waste glass melter feeds discussed above. To the extent possible, the temperature ranges in which these reactions occur are estimated. These are generally the temperatures at which the reactions would be expected in relatively pure mixtures of the reactants, and it is recognized that in the complex nuclear waste glass mixture the presence of other materials may force reactions to occur at lower temperatures. Since many of these reactions are controlled by kinetics, the presence of low melting eutectics in complex mixtures will produce fluxes that allow reactions to begin to proceed faster at lower temperatures than they would if a liquid phase were not present. There should be, though, some major differences in the chemistry occurring with the different feed categories described above.

The general thermal chemistry of the various redox species, such as multivalent metal ions, nitrate, nitrite, formate, and other reducing agents are discussed separately. This material is followed by separate discussions of how redox chemistry is altered by the various feed categories (alkaline, acidic, acidic reduced, and alkaline reduced) defined above. Alkaline wastes are discussed first because they 
correspond to Hanford, Savannah River, and West Valley wastes as they come from the waste storage tanks without treatment such as formating, because they appear to produce the greatest foaming (Goldman, Brite, and Richey 1986), and because they should result in the highest amount of highly oxidized multivalent metal ions surviving to high temperatures.

With most multivalent transition elements, the presence of alkali $\left(\mathrm{OH}^{-}, \mathrm{O}^{2-}\right)$ markedly favors formation of high oxidation states in the presence of various oxidants. This is because many of these elements form oxygenated ions in their higher oxidation states. Thus, low oxidation state $\mathrm{Cr}, \mathrm{Mn}, \mathrm{Fe}$, and Ni compounds with oxidants can produce higher oxidation state species through reactions that are promoted by alkali. Several of these alkali-influenced reactions can take place in the cold cap as the feed is dehydrated and heated to glass-forming temperatures. In the glass melt itself, Paul (1982, p. 159) noted, "All experiments on redox equilibrium reported in the literature show that the proportion of the redox ion in the higher oxidation state increases with the basicity of the glass." Some of the higher oxidation state products formed in the cold cap will not survive to $1150^{\circ} \mathrm{C}$ (the final glass temperature), but some will. In all cases, forming these species in the cold cap ensures that these metals will be in the highest oxidation states that are thermally stable. It will also ensure that oxygen is held in the melt to the highest temperatures at which these species are thermodynamically stable.

\subsection{Oxidants in the Melter Feed or Formed in the Cold Cap}

\subsubsection{Manganese}

The following reactions are known to occur when Mn compounds are heated:

$$
\begin{gathered}
\mathrm{Mn}\left(\mathrm{NO}_{3}\right)_{2} \cdot \mathrm{yH}_{2} \mathrm{O} \rightarrow \mathrm{MnO}_{2}+2 \mathrm{NO}_{2}+\mathrm{yH}_{2} \mathrm{O} \\
\left.\mathrm{Mn}(\mathrm{OH})_{2} \text { (or } \mathrm{MnO}\right)+\mathrm{O}_{2} \rightarrow \mathrm{MnO}_{2} \\
2 \mathrm{MnO}_{2}+6 \mathrm{KOH}+1 / 2 \mathrm{O}_{2} \rightarrow 2 \mathrm{~K}_{3} \mathrm{MnO}_{4}+3 \mathrm{H}_{2} \mathrm{O} \\
2 \mathrm{~K}_{3} \mathrm{MnO}_{4}+\mathrm{H}_{2} \mathrm{O}+1 / 2 \mathrm{O}_{2} \rightarrow 2 \mathrm{~K}_{2} \mathrm{MnO}_{4}+2 \mathrm{KOH} \\
\mathrm{MnO}_{2}+2 \mathrm{KOH}+1 / 2 \mathrm{O}_{2} \rightarrow \mathrm{K}_{2} \mathrm{MnO}_{4}+\mathrm{H}_{2} \mathrm{O} \\
\mathrm{MnO}_{2}+\mathrm{KNO}_{3}+\mathrm{KOH} \rightarrow \mathrm{K}_{2} \mathrm{MnO}_{4}
\end{gathered}
$$

Reaction (2) proceeds at $130^{\circ}$ to $140^{\circ} \mathrm{C}$ (Hay 1952, p. 743) and is a preparative method for making $\mathrm{MnO}_{2}$ at $145^{\circ}$ to $160^{\circ} \mathrm{C}$ (Bailar et al. 1973c, p. 802). Reaction (3) proceeds slowly with $\mathrm{MnO}$ and air at $25^{\circ} \mathrm{C}$ (Bailar et al. 1973c, p. 799; Cotton and Wilkinson 1972, p. 747) and rapidly with $\mathrm{Mn}(\mathrm{OH})_{2}$ 
and air at $25^{\circ} \mathrm{C}$. Reaction (4) goes to completion in less than $1 \mathrm{~min}$ in air at $390^{\circ}$ to $420^{\circ} \mathrm{C}$ when finely ground $\mathrm{MnO}_{2}$ (pyrolusite ore) suspended in $50 \% \mathrm{KOH}$ is sprayed into a rotary kiln or spray chamber as a step in $\mathrm{KMnO}_{4}$ manufacturing (Reidies 1981, p. 870). Reaction (4) also occurs with $\mathrm{NaOH}$ (Reidies 1981, pp. 857-859). Reaction (5) occurs more slowly (3 to $4 \mathrm{~h}$ for completion) in air containing $300 \mathrm{~g} \mathrm{H}_{2} \mathrm{O} / \mathrm{m}^{3}$ in a fluid bed or rotary kiln at $180^{\circ}$ to $220^{\circ} \mathrm{C}$. This is also a step in the manufacture of $\mathrm{KMnO}_{4}$, and reaction (5) apparently does not occur with $\mathrm{NaOH}$ replacing $\mathrm{KOH}$ and with $\mathrm{O}_{2}$ as the oxidant (Reidies 1981, pp. 857-859). Reaction (6) corresponds to the net of reactions (4) and (5). Reaction (7) (not balanced because the nature of the nitrogen species in the product was not reported) is reported by Molinari and Margrave (1964) to become observable at $170^{\circ} \mathrm{C}$ at atmospheric pressure and to occur explosively at high pressure at temperatures as low as $100^{\circ} \mathrm{C}$. In the absence of $\mathrm{KOH}$, no reaction occurred up to significantly higher temperatures, indicating the importance of $\mathrm{OH}^{-}\left(\right.$or $\left.\mathrm{O}^{2-}\right)$ to these reactions.

The reported reaction of $\mathrm{Na}_{2} \mathrm{O}_{2}$ in $\mathrm{NaNO}_{2}$ at $500^{\circ} \mathrm{C}$ to form $\mathrm{Na}_{3} \mathrm{MnO}_{4}$ (Hay 1952, p. 750) and the reaction of $\mathrm{MnO}_{2}, \mathrm{KOH}$, and air at $600^{\circ}$ to $800^{\circ} \mathrm{C}$ to form $\mathrm{K}_{3} \mathrm{MnO}_{4}$ (Reidies 1981, p. 750) indicate the relatively high temperature stability of $\mathrm{Mn}(\mathrm{V})$. Peters, Redeke, and Till (1966) studied the thermal stability of potassium manganates and gave the following reactions occurring at the temperatures shown:

$$
\begin{gathered}
5 \mathrm{KMnO}_{4} \stackrel{240^{\circ}-300^{\circ} \mathrm{C}}{\rightarrow} \mathrm{K}_{2} \mathrm{MnO}_{4}+\dot{\mathrm{K}}_{3} \mathrm{MnO}_{4}+3 \mathrm{MnO}_{2}+3 \mathrm{O}_{2} \\
3 \mathrm{~K}_{2} \mathrm{MnO}_{4} \stackrel{-640^{\circ}-680^{\circ} \mathrm{C}}{\rightarrow} 2 \mathrm{~K}_{3} \mathrm{MnO}_{4}+1 / 2 \mathrm{Mn}_{2} \mathrm{O}_{3}+5 / 4 \mathrm{O}_{2} \\
\mathrm{~K}_{3} \mathrm{MnO}_{4} \stackrel{-850^{\circ}-1100^{\circ} \mathrm{C}}{\rightarrow} 3 / 2 \mathrm{~K}_{2} \mathrm{O}+1 / 3 \mathrm{Mn}_{3} \mathrm{O}_{4}+7 / 12 \mathrm{O}_{2}
\end{gathered}
$$

The fact that in reaction (8), three $\mathrm{Mn}$ oxidation states and in reaction (9) two Mn oxidation states are formed is a result of the limited quantity of available alkali. This demonstrates that alkali markedly stabilizes the manganates. Peters, Radeke, and Till (1966) estimated that pure $\mathrm{K}_{3} \mathrm{MnO}_{4}$ is stable in air to a temperature of about $1100^{\circ} \mathrm{C}$.

Weyl (1951, pp. 127-131) and Volf (1984, pp. 340-347) discuss reactions that occur during melting of Mn-containing commercial glass batches. When the source of alkali is $\mathrm{Na}_{2} \mathrm{CO}_{3}$ (as in commercial glasses), there is a decrease in the average oxidation state of $\mathrm{Mn}$ added as $\mathrm{MnO}_{2}$ above about $500^{\circ} \mathrm{C}$, followed by an increase at around $800^{\circ} \mathrm{C}$. This increase, which is caused by formation of manganate, occurs around $700^{\circ}$ to $800^{\circ} \mathrm{C}$, presumably because the decomposition pressure of the rather stable $\mathrm{Na}_{2} \mathrm{CO}_{3}$ (Duval 1963, p. 458) is insufficient to provide adequate alkali $\left(\mathrm{Na}_{2} \mathrm{O}\right)$ activity at lower temperatures. The oxidizing agent for this phenomena is either air or sodium nitrate, which is often added to $\mathrm{Mn}$-containing commercial glasses. These higher Mn oxidation states decompose to $\mathrm{Mn}$ (II) and $\mathrm{Mn}$ (III) above about $800^{\circ}$ to $900^{\circ} \mathrm{C}$. Two factors then combine to cause this manganate decomposition, $\mathrm{O}_{2}$ release, and average $\mathrm{Mn}$ oxidation state decrease above $\sim 800^{\circ} \mathrm{C}$. One factor is the simple decrease in thermal stability of the manganates to produce $\mathrm{Mn}$ (III) and $\mathrm{Mn}$ (II). The other factor is increased dissolution of sand $\left(\mathrm{SiO}_{2}\right)$, which decreases the melt alkalinity and further destabilizes the 
manganates. Only Mn(III) and (II) are expected in borosilicate glass at $1150^{\circ} \mathrm{C}$. Schrieber's (1984) data indicate that at $1150^{\circ} \mathrm{C}$ borosilicate waste glass in equilibrium with air would have about $10 \%$ $\mathrm{Mn}(\mathrm{III})$.

In alkaline nuclear waste glass feeds having significant $\mathrm{OH}^{-}$activity and alkali nitrate and/or nitrite, oxidation to manganate [probably $\mathrm{Mn}(\mathrm{VI})$ ] can be expected to occur at low temperatures (beginning at about $170^{\circ} \mathrm{C}$ ). There is certainly enough $\mathrm{NaNO}_{3}$ (and even more $\mathrm{NaNO}_{2}$ ) ${ }^{(\mathrm{a})}$ in anticipated Hanford waste glass feeds to oxidize all $\mathrm{Mn}$ to manganates (and $\mathrm{Cr}$ to chromates also, as discussed below). If the $\mathrm{OH}^{-}$level in the feed is as projected, ${ }^{(a)}$ there should also be enough of it regardless of whether nitrate or nitrite is the oxidant and whether $\mathrm{N}_{2}$ or NO is the reduction product.

\subsubsection{Chromium}

The following reactions are known to occur when $\mathrm{Cr}$ compounds are heated:

$$
\begin{gathered}
2 \mathrm{Cr}\left(\mathrm{NO}_{3}\right)_{3} \cdot \mathrm{yH}_{2} \mathrm{O} \rightarrow \mathrm{Cr}_{2} \mathrm{O}_{3}+6 \mathrm{NO}_{\mathrm{x}}+\mathrm{yH}_{2} \mathrm{O}+(15-6 \mathrm{x}) / 2 \mathrm{O}_{2} \\
\mathrm{Cr}_{2} \mathrm{O}_{3}+3 / 2 \mathrm{O}_{2}+4 \mathrm{OH}^{-} \rightarrow 2 \mathrm{CrO}_{4}^{2-}+2 \mathrm{H}_{2} \mathrm{O} \\
4 \mathrm{FeCr}_{2} \mathrm{O}_{4}+8 \mathrm{Na}_{2} \mathrm{CO}_{3}+7 \mathrm{O}_{2} \rightarrow 2 \mathrm{Fe}_{2} \mathrm{O}_{3}+8 \mathrm{Na}_{2} \mathrm{CrO}_{4}+8 \mathrm{CO}_{2} \\
\mathrm{Cr}_{2} \mathrm{O}_{3}+2 \mathrm{NaNO}_{3} \rightarrow \mathrm{Na}_{2} \mathrm{Cr}_{2} \mathrm{O}_{7}+2 \mathrm{NO} \\
\mathrm{Cr}_{2} \mathrm{O}_{3}+2 \mathrm{NaNO}_{3}+2 \mathrm{NaOH} \rightarrow 2 \mathrm{Na}_{2} \mathrm{CrO}_{4}+2 \mathrm{NO}+\mathrm{H}_{2} \mathrm{O}
\end{gathered}
$$

Reaction (11) with $\mathrm{y} \sim 9$ proceeds smoothly from near $100^{\circ} \mathrm{C}$ to about $680^{\circ} \mathrm{C}$ with simultaneous loss of water and nitrate. There appears to be at least marginal stability of an intermediate of approximate formula $\mathrm{Cr}(\mathrm{OH})_{2} \mathrm{NO}_{3}$, (Duval 1963, p. 308). The temperature conditions at which reactions (12) and (15) readily progress were not found, but it is assumed that these reactions will occur in the same temperature range as the similar reactions for Mn discussed above and for Fe discussed below. Reaction (13), using natural chromite ore and sodium carbonate, is carried out commercially at temperatures up to $1100^{\circ}$ to $1150^{\circ} \mathrm{C}$ as a starting route to many $\mathrm{Cr}$ compounds (Hartford and Copson 1964, p. 484).

If the more basic $\mathrm{NaOH}$ along with $\mathrm{NaNO}_{3}$ and $\mathrm{Cr}_{2} \mathrm{O}_{3}$ were used (reaction 15), a much lower reaction temperature is expected to result. Indeed, Sugiyama and Takahashi (1967a) reported that $\mathrm{Cr}_{2} \mathrm{O}_{3}$ and $\mathrm{NaNO}_{3}$ alone, without $\mathrm{NaOH}$, begin to react at $300^{\circ}$ to $400^{\circ} \mathrm{C}$ and react rapidly at $480^{\circ}$ to $500^{\circ} \mathrm{C}$, producing $\mathrm{NO}$ as the product gas. The presence of $\mathrm{NaOH}$ should further lower the reaction

(a) Smith, R. A. 1991. Revision of Pretreated Neutralized Current Acid Waste Composition for FY 1991 Pilot Testing. Westinghouse Hanford Company letter to Mr. J. M. Creer, January 21, 1991, Correspondence No. 9150110. 
temperature, quite possibly to the same range as for the reaction with $\mathrm{MnO}_{2}$ (reaction 7). Sugiyama and Takahashi found up to $95 \% \mathrm{NO}$ at equimolar or greater amounts of $\mathrm{Cr}_{2} \mathrm{O}_{3}$ relative to $\mathrm{NaNO}_{3}$ corresponding to reaction (14) above. The reaction began in the $300^{\circ}$ to $400^{\circ} \mathrm{C}$ range and proceeded rapidly at $480^{\circ}$ to $500^{\circ} \mathrm{C}$. They found lower reaction rates with $\mathrm{NaNO}_{2}$ and not greater than $65 \%$ of the gas as NO. This is no doubt related to the fact that $\mathrm{NaNO}_{2}$ cannot react stoichiometrically in the absence of free base to produce only $\mathrm{Na}_{2} \mathrm{CrO}_{4}$ and/or $\mathrm{Na}_{2} \mathrm{Cr}_{2} \mathrm{O}_{7}$ and $\mathrm{NO}$, but must instead produce either excess $\mathrm{Na}_{2} \mathrm{O}$ or a lower nitrogen oxidation state gas (presumably $\mathrm{N}_{2}$ and/or $\mathrm{N}_{2} \mathrm{O}$ ). It is presumed that at relatively low temperatures, producing $\mathrm{N}_{2}$ or $\mathrm{N}_{2} \mathrm{O}$ is probably more difficult (from the standpoint of kinetic mechanisms) than producing $\mathrm{NO}$, thus explaining the lower reaction rates with $\mathrm{NaNO}_{2}$.

Although $\mathrm{NaNO}_{2}$ cannot react with $\mathrm{Cr}_{2} \mathrm{O}_{3}$ to produce only $\mathrm{Na}_{2} \mathrm{CrO}_{4}$ and/or $\mathrm{Na}_{2} \mathrm{Cr}_{2} \mathrm{O}_{7}$, and $\mathrm{NaNO}_{3}$ cannot react (in the absence of added free base) with $\mathrm{Cr}_{2} \mathrm{O}_{3}$ to produce only $\mathrm{Na}_{2} \mathrm{CrO}_{4}$ and $\mathrm{NO}$, a mixture of $\mathrm{NaNO}_{3}$ and $\mathrm{NaNO}_{2}$ can produce only $\mathrm{NO}$ and $\mathrm{Na}_{2} \mathrm{CrO}_{4}$ :

$$
\mathrm{Cr}_{2} \mathrm{O}_{3}+\mathrm{NaNO}_{3}+3 \mathrm{NaNO}_{2} \rightarrow 2 \mathrm{Na}_{2} \mathrm{CrO}_{4}+4 \mathrm{NO}
$$

This reaction has been used as a dry route preparation of virtually pure $(99.8 \%)$ NO proceeding at a reasonable rate at $310^{\circ} \mathrm{C}$ (Ray and Ogg 1956). The reaction product (using a two-fold excess of $\mathrm{Cr}_{2} \mathrm{O}_{3}$ ) contained only a trace of $\mathrm{Na}_{2} \mathrm{Cr}_{2} \mathrm{O}_{7}$, indicating that $\mathrm{Na}_{2} \mathrm{CrO}_{4}$ is apparently the preferred product (reaction 16 over 14). Also, as the amount of $\mathrm{NaNO}_{3}$ was decreased relative to $\mathrm{NaNO}_{2}$, both $\mathrm{N}_{2}$ and $\mathrm{N}_{2} \mathrm{O}$ began to appear in the gaseous product.

This reaction (16) is potentially of considerable importance to redox chemistry in the cold caps. The $\mathrm{NaNO}_{2} / \mathrm{NaNO}_{3}$ ratio in projected NCAW feed is 3.75 , which is reasonably close to that required by reaction (16). It seems reasonable to assume that both $\mathrm{Mn}$ and Fe may show similar reactions with nitrate-nitrite mixtures to form ferrates and manganates. The stoichiometry would be the same as reaction (16) for ferrates; the situation is much more complex with $\mathrm{Mn}$ since the starting material can be postulated as either $\mathrm{MnO}, \mathrm{Mn}_{2} \mathrm{O}_{3}, \mathrm{Mn}_{3} \mathrm{O}_{4}$, or $\mathrm{MnO}_{2}$, with $\mathrm{MnO}$ least likely. Oxidation of $\mathrm{MnO}_{2}$ to $\mathrm{MnO}_{4}^{2-}$ by $\mathrm{NaNO}_{2}$ yielding only $\mathrm{NO}$ requires no free base, and $\mathrm{Mn}_{2} \mathrm{O}_{3}$ could react by the same stoichiometry as reaction (16). On the other hand, if $\mathrm{Mn}_{3} \mathrm{O}_{4}$ or $\mathrm{MnO}$ are to react without using or producing free base to produce NO as the only nitrogen-containing product, they not only require mixtures of $\mathrm{NaNO}_{3}$ and $\mathrm{NaNO}_{2}$, but also must produce both $\mathrm{Na}_{2} \mathrm{MnO}_{4}$ and $\mathrm{Na}_{3} \mathrm{MnO}_{4}$. The important point is that for alkaline waste, very little excess base would be required if an appropriate nitrate/nitrite ratio is present. In acidic waste, excess base is not present to form manganates, chromates, etc., and nitrite is decomposed so that reactions such as (16) also cannot occur at temperature below that at which nitrate is thermally converted to nitrite.

The reaction temperature for reaction $(13)\left(1100^{\circ}\right.$ to $\left.1500^{\circ} \mathrm{C}\right)$ indicates that chromate is more stable than the various manganates, and indeed, Schrieber's (1984) data for simulated borosilicate waste glass indicate that $\mathrm{Cr}$ would be near $50 \%$ hexavalent at $1150^{\circ} \mathrm{C}$ in equilibrium with air.

Alkaline earth chromates (IV) and alkali chromates (V) are known (Bailar et al. 1973c, pp. 688-691), but appear to be less stable relative to chromate (VI) and $\mathrm{Cr}$ (III) than manganate (V) relative to manganate (VI) and $\mathrm{Mn}$ (III). Chromium apparently exists in glass only as $\mathrm{Cr}$ (VI) or $\mathrm{Cr}(\mathrm{III})$, often coexisting in variable ratio depending on the degree of oxidation or reduction, and as $\mathrm{Cr}(\mathrm{II})$ under 
conditions of very strong reduction (Volf 1984, p. 334). At the lower temperatures of the cold cap, particularly in the presence of lower melting fluxes (such as $\mathrm{NaOH}, \mathrm{NaNO}_{3}, \mathrm{NaNO}_{2}$, and their mixtures), $\mathrm{Cr}(\mathrm{IV})$ and (V) might form, but with excess $\mathrm{NaNO}_{3}$ or $\mathrm{NaNO}_{2}$ these should convert to $\mathrm{Cr}(\mathrm{VI})$.

\subsubsection{Cerium}

The following reactions are known to occur with $\mathrm{Ce}$ (III) compounds:

$$
\begin{gathered}
\mathrm{Ce}\left(\mathrm{OH}_{3}\right)+1 / 4 \mathrm{O}_{2} \rightarrow \mathrm{CeO}_{2}+3 / 2 \mathrm{H}_{2} \mathrm{O} \\
\mathrm{Ce}\left(\mathrm{NO}_{3}\right)_{3} \cdot \mathrm{yH}_{2} \mathrm{O} \rightarrow \mathrm{CeO}_{2}+\mathrm{yH}_{2} \mathrm{O}+\mathrm{NO}_{\mathrm{x}}
\end{gathered}
$$

Reaction (17) proceeds slowly in air at $25^{\circ} \mathrm{C}$ in aqueous suspension to produce the hydrated form of $\mathrm{CeO}_{2}$, and the reaction goes readily to virtual completion at a few hundred degrees. With $\mathrm{y}=6$ in reaction (18), loss of water begins at $80^{\circ} \mathrm{C}$, and complete conversion to $\mathrm{CeO}_{2}$ is reached by $450^{\circ} \mathrm{C}$ (Duval 1963, p. 544). Stable intermediates do not appear to form in the thermal decomposition of cerous nitrate.

Oxidation states of $\mathrm{Ce}$ other than $\mathrm{Ce}$ (III) and (IV) are unknown. Although $\mathrm{Ce}$ (IV), along with tetravalent actinides, can form double oxide compounds with alkali and alkaline earth elements, it does not appear (Keller 1972) that they contain discrete Ce(IV) oxygenated anions like the d-group transition elements discussed here (chromates, manganates, etc.). Nevertheless, as with all other redox equilibria studied in glasses, increasing glass basicity, either by increasing $\mathrm{M}_{2} \mathrm{O}$ content or by going from $\mathrm{Li}_{2} \mathrm{O}$ through $\mathrm{Na}_{2} \mathrm{O}$ to $\mathrm{K}_{2} \mathrm{O}$ as the alkali oxide glass component at constant $\mathrm{M}_{2} \mathrm{O}$ content, increases the equilibrium Ce(IV)/Ce(III) ratio at a given temperature (Paul 1982, pp. 159-160). The effect is not as pronounced though, as in the case of the $\mathrm{Cr}(\mathrm{Vl}) / \mathrm{Cr}(\mathrm{III})$ couple where $\mathrm{Cr}(\mathrm{VI})$ forms $\mathrm{CrO}_{4}^{2-}$. It can be reasonably assumed that in the cold cap with nitrate or nitrite present or in the presence of air, essentially all Ce will be converted to Ce(IV) by $450^{\circ} \mathrm{C}$ and that at glass-forming temperatures and above, $\mathrm{O}_{2}$ evolution will occur to establish a temperature-dependent equilibrium ratio of $\mathrm{Ce}$ (IV)/Ce(III). At $1150^{\circ} \mathrm{C}$, this ratio will be near unity for borosilicate waste glass in equilibrium with air, similar to the case of $\mathrm{Cr}$ (VI)/Cr(III) (Schreiber et al. 1984).

\subsubsection{Nickel}

Nickel reacts with various oxidants in alkaline systems, either aqueous or anhydrous, to form various double oxide or hydroxide compounds with the alkali metals in which $\mathrm{Ni}$ is in the (III) or (IV) oxidation state (Bailar et al. 1973c, pp. 1159-1160). Thus, reaction of $\mathrm{Ni}$ metal with $\mathrm{NaOH}$ and $\mathrm{Na}_{2} \mathrm{O}_{2}$ at $600^{\circ} \mathrm{C}$, followed by leaching the sodium salts away with ice water, leaves the compound $\mathrm{NiO}(\mathrm{OH})$ (Glemser and Einerhand 1950). Both $\mathrm{M}_{2} \mathrm{NiO}_{2.5}$ and $\mathrm{M}_{2} \mathrm{NiO}_{3}$ are obtained by heating $\mathrm{NiO}$ with $\mathrm{Na}_{2} \mathrm{O}$ in $\mathrm{O}_{2}$ (Bade, Bronger, and Klemm 1965). It is also reported that bubbling $\mathrm{O}_{2}$ through alkali metal hydroxides at about $800^{\circ} \mathrm{C}$ in Ni crucibles produces $\mathrm{MNiO}_{2}$ (Cotton and Wilkinson 1972, p. 901). 
Based on the above, it can certainly be expected that in cold caps containing $\mathrm{NaNO}_{3}$ and adequate $\mathrm{NaOH}, \mathrm{Ni}$ will be oxidized to above $\mathrm{Ni}(\mathrm{II})$. This higher oxidation state $\mathrm{Ni}$ will persist until at least $800^{\circ} \mathrm{C}$ or until sufficient silica dissolves into the melt to significantly decrease the melt alkalinity. Schrieber's (1984) data indicate that in the final borosilicate waste glass at $1150^{\circ} \mathrm{C}$, only about $1.5 \%$ $\mathrm{Ni}$ (III) will coexist with $\mathrm{Ni}$ (II) in equilibrium with air. Thus, like the manganates, $\mathrm{Mn}$ (III) and the ferrates discussed below, higher oxidation state $\mathrm{Ni}$ species will have released most of their potential oxygen yield below $1150^{\circ} \mathrm{C}$.

\subsubsection{Iron}

The following reactions are known to occur when Fe compounds are heated:

$$
\begin{gathered}
\mathrm{Fe}\left(\mathrm{NO}_{3}\right)_{3} \cdot 9 \mathrm{H}_{2} \mathrm{O} \rightarrow \mathrm{Fe}_{2} \mathrm{O}_{3}+\mathrm{NO}_{\mathrm{x}}+\mathrm{H}_{2} \mathrm{O}+\mathrm{O}_{2} \\
2 \mathrm{FeO}+1 / 2 \mathrm{O}_{2} \text { (air) } \rightarrow \mathrm{Fe}_{3} \mathrm{O}_{4} \\
3 \mathrm{Fe}_{2} \mathrm{O}_{3} \rightarrow \mathrm{Fe}_{3} \mathrm{O}_{4}+1 / 2 \mathrm{O}_{2} \\
1 / 2 \mathrm{Fe}_{2} \mathrm{O}_{3}+\mathrm{NaOH} \rightarrow \mathrm{NaFeO}_{2}+1 / 2 \mathrm{H}_{2} \mathrm{O} \\
\mathrm{Fe}_{2} \mathrm{O}_{3}+3 / 2 \mathrm{O}_{2}(\text { air })+4 \mathrm{OH}^{-} \rightarrow 2 \mathrm{FeO}_{4}^{2-}+2 \mathrm{H}_{2} \mathrm{O} \\
\mathrm{Fe}+\mathrm{KNO}_{3} \rightarrow \mathrm{K}_{2} \mathrm{FeO}_{4} \\
\mathrm{Fe}_{2} \mathrm{O}_{3}+\mathrm{KNO}_{3}+\mathrm{KOH} \rightarrow \mathrm{K}_{2} \mathrm{FeO}_{4}
\end{gathered}
$$

In reaction (19), Duval (1963, pp. 328-329; Duval 1959b) reported loss of water began at $38^{\circ} \mathrm{C}$, and decomposition giving off $\mathrm{NO}_{\mathrm{x}}$ began at $120^{\circ} \mathrm{C}$. There was some indication of an intermediate at $120^{\circ} \mathrm{C}$, and decomposition was essentially complete at $160^{\circ} \mathrm{C}$ with traces of $\mathrm{NO}_{\mathrm{x}}$ released to about $310^{\circ} \mathrm{C}$ where $\mathrm{Fe}_{3} \mathrm{O}_{4}$ was the product. It seems very unlikely that $\mathrm{Fe}_{3} \mathrm{O}_{4}$ would be the product of the nitrate decomposition. Since $\mathrm{Fe}_{3} \mathrm{O}_{4}$ production in the cold cap from acidic feeds containing ferric nitrate could have significant consequences on potential glass-foaming chemistry, an attempt was made to find other studies of ferric nitrate thermal decomposition. Purtov et al. (1970) reported melting of ferric nitrate nonahydrate at $58^{\circ} \mathrm{C}$, loss of three $\mathrm{H}_{2} \mathrm{O}$ molecules at $104^{\circ}$ to $134^{\circ} \mathrm{C}$, a weight loss of $45.5 \%$ by $152^{\circ} \mathrm{C}$, and complete conversion to $\alpha-\mathrm{Fe}_{2} \mathrm{O}_{3}$ at $250^{\circ} \mathrm{C}$. These data certainly do not agree with the thermogram published by Duval (1959b). 
Other references to thermal decomposition of ferric nitrate hydrate were found in Chemical Abstracts (CA), but the original papers (some not in English) were not obtained. Gadalla and Hennicke (1973) indicated that when $\mathrm{Fe}\left(\mathrm{NO}_{3}\right)_{3} \cdot 9 \mathrm{H}_{2} \mathrm{O}$ is decomposed at $200^{\circ} \mathrm{C}$ the product is $\alpha-\mathrm{Fe}_{2} \mathrm{O}_{3}$. Lumme and Junkkarinen (1968) carried out thermogravimetric studies of $\mathrm{Fe}\left(\mathrm{NO}_{3}\right)_{3} \cdot 9 \mathrm{H}_{2} \mathrm{O}$ and other ferric salts in air, and Muzyka et al. (1968) performed differential thermal analysis studies of ferric nitrate. The abstracts (CA) of these last two publications do not identify which oxide was obtained. Kerridge and Khudari (1975) reacted both ferrous and ferric salts (ferrous sulfate, carbonate, and sulfate; and ferric chloride and oxynitrate) with molten $\mathrm{LiNO}_{3}-\mathrm{KNO}_{3}$, and in all cases the product was reported as $\mathrm{Fe}_{2} \mathrm{O}_{3}$. Based on these reports, the product of reaction (19) certainly appears to be $\mathrm{Fe}_{2} \mathrm{O}_{3}$, but because of the significance of this, further confirmation may be desirable.

Reaction (20) occurs at low temperature, and in fact, $\mathrm{FeO}$ is not thermodynamically stable at $25^{\circ} \mathrm{C}$ relative to $\mathrm{Fe}$ and $\mathrm{Fe}_{3} \mathrm{O}_{4}$. The oxidation rate in reaction (20) will, of course, depend on the surface area and temperature. But with high surface area material, reaction (20) can be rapid (pyrophoric), even at low temperatures (Bailar et al. 1973c, pp. 1008-1009). This reaction is not expected to occur in heating nuclear waste feeds, but would be expected to occur at low temperature if $\mathrm{FeO}$ were deliberately used in simulated feeds.

Reaction (21) proceeds to the right as shown in air only at temperatures above $1400^{\circ} \mathrm{C}$. At lower temperatures, the reaction is reversed and $\mathrm{Fe}_{3} \mathrm{O}_{4}$ is oxidized to $\mathrm{Fe}_{2} \mathrm{O}_{3}$. Thus, from reactions (20) and (21), it is expected that relatively low temperature ignition of iron salts or hydrous oxides in air would produce $\mathrm{Fe}_{2} \mathrm{O}_{3}$.

Reaction (22) indicates the amphoteric nature of Fe(III) (Cotton and Wilkinson 1972, p. 864). Formation of such species can be expected to stabilize Fe(III) relative to Fe(II) as the system basicity is increased. It has been proposed that $\mathrm{Fe}(\mathrm{III})$ exists in glass as the $\mathrm{FeO}_{2}^{-}$anion (Goldman and $\mathrm{Brite}$ 1986; Lucktong and Hrma 1988 and references therein). There is virtually no likelihood that the $\mathrm{FeO}_{2}^{-}$ion even exists since Fe(III) would be only 2-coordinate in such a species. Most ferrates(III) as well as aluminates in which the stoichiometry matches $\mathrm{MO}_{2}^{-}$are spinels with $\mathrm{Fe}$ (III) 6-coordinate to shared oxygens. It has certainly been observed that the stability of $\mathrm{Fe}(\mathrm{III})$ increases as alkalinity increases, either by increasing the $\mathrm{M}_{2} \mathrm{O}$ content or by going from $\mathrm{Li}_{2} \mathrm{O}$ through $\mathrm{Na}_{2} \mathrm{O}$ to $\mathrm{K}_{2} \mathrm{O}$ in alkali silicate melts (Paul 1982, p. 159), but it is not necessary to invoke the existence of an $\mathrm{FeO}_{2}^{-}$ion in these glasses to explain such behavior. Although $\mathrm{NaFeO}_{2}$ no doubt forms in the cold cap with alkaline feeds, its formation should have little influence on $\mathrm{Fe}$ oxidation state in the absence of a reductant since Fe(III) would be the stable oxidation state relative to Fe(II) in the cold cap even with an acidic feed.

In the older literature, reaction (23) is reported to proceed slowly when $\mathrm{Fe}_{2} \mathrm{O}_{3}$ and $\mathrm{KOH}$ are heated in air (Mellor 1934, pp. 929-937). Reaction (24) is reported to occur at a dull red heat and was at one time used to prepare $\mathrm{K}_{2} \mathrm{FeO}_{4}$ (Mellor 1934, pp. 929-937). Reaction (25) was reportedly a better route for preparing $\mathrm{K}_{2} \mathrm{FeO}_{4}$. It was recommended that the reactant mixture be "strongly ignited" to destroy $\mathrm{KNO}_{2}$ since the $\mathrm{K}_{2} \mathrm{FeO}_{4}$ produced was recrystallized from water solution, and nitrite reduced it in water and lowered the yield. Thus, $\mathrm{Fe}(\mathrm{VI})$ would appear to be reasonably stable in excess $\mathrm{KOH}$ to temperatures of about $800^{\circ} \mathrm{C}$ or possibly higher.

More detailed or recent work on ferrate formation and stability in nitrate-hydroxide melts was not found, apparently because strictly aqueous methods of preparing ferrates (VI) have replaced the dry thermochemical routes and have lowered interest in the dry thermal reactions. Data on the stability of $\mathrm{K}_{2} \mathrm{FeO}_{4}$ in $\mathrm{LiNO}_{3}$ eutectic melts in the absence of free hydroxide indicate slow decomposition in the 
temperature range $160^{\circ}$ to $250^{\circ} \mathrm{C}$, producing $\mathrm{Fe}$ oxides higher than $\mathrm{Fe}_{2} \mathrm{O}_{3}$ (Kerridge and Khudhari 1975). After $26 \mathrm{~h}$ at $250^{\circ} \mathrm{C}$, the solid phase that formed corresponded to approximately the composition $\mathrm{FeO}_{2}$. Thermogravimetric analysis of $\mathrm{K}_{2} \mathrm{FeO}_{4}$ in molten $\mathrm{LiNO}_{3}-\mathrm{KNO}_{3}$ eutectic indicated a small weight loss $(\sim 4 \%)$ at $140^{\circ}$ to $200^{\circ} \mathrm{C}$ and a larger loss $(\sim 9 \%)$ at $320^{\circ}$ to $450^{\circ} \mathrm{C}$. With $\mathrm{K}_{2} \mathrm{FeO}_{4}$ alone under either air or $\mathrm{N}_{2}$, similar losses occurred at $230^{\circ}$ to $300^{\circ} \mathrm{C}$ and at $450^{\circ}$ to $550^{\circ} \mathrm{C}$. With excess hydroxide, stability of ferrate to higher temperatures can be expected.

Ferrate is sufficiently unstable to decompose at a temperature at least no higher than the silica reaction temperature (initial batch melting temperature) of about $700^{\circ}$ to $800^{\circ} \mathrm{C}$. The silica dissolution and the consequent melt acidification should decompose any $\mathrm{Na}_{2} \mathrm{FeO}_{4}$ at the glass-forming temperature. The remaining Fe(III) does not begin to decompose at atmospheric pressures in borosilicate waste glasses until about $1150^{\circ} \mathrm{C}$ (Schreiber et al. 1984), and in both borosilicate and other silicate melts, temperatures from $1150^{\circ}$ to $1500^{\circ} \mathrm{C}$ are required to produce a significant amount of gas from $\mathrm{Fe}$ (III) decomposition. The uranium (VI-V) and (V-IV) couples are expected to be similar to the Fe(III-II) couple with $U(V I)$ being a slightly stronger and $U(V)$ a slightly weaker oxidant than Fe(III) (Schreiber et al. 1984).

Iron will be by far the most plentiful multivalent metal present in feed to nuclear waste glass melters. For anticipated NCAW feed slurry, ${ }^{(a)} \mathrm{Fe}$ concentration is $0.44 \mathrm{M}$, whereas the sum of $\mathrm{Mn}, \mathrm{Cr}$, $\mathrm{Ce}$, and $\mathrm{Ni}$ is $0.078 \underline{\mathrm{M}}$. These values compare to anticipated values of $0.116 \underline{\mathrm{M} \mathrm{NO}}{ }_{3}^{-}$and $0.435 \underline{\mathrm{M}}$ $\mathrm{NO}_{2}^{-}$, which are adequate to oxidize all the above metals if both nitrate and nitrite react. The amount of hydroxide in the feed slurry is less certain and depends on the nature of the tank sludge washing. It should be apparent that if a significant fraction of the $\mathrm{NaNO}_{3}$ and $\mathrm{NaNO}_{2}$ remain after sludge washing, some of the initial tank hydroxide will remain. Also, researchers believe that to wash away $\mathrm{NaAlO}_{2}$ from the sludge, the wash solution must be at least $\sim 0.1 \mathrm{M} \mathrm{OH}$ to prevent aluminum hydroxide precipitation (G. J. Lumetta, PNL, personal communication). This would indicate that free hydroxide (and $\mathrm{NaAlO}_{2}$, which is also a rather strong base) will probably be at least $0.1 \underline{\mathrm{M}}$ and possibly $0.2 \underline{\mathrm{M}}$. At this concentration range, hydroxide (or oxide) ion would be the limiting reagent in the formation of manganates, chromates, nickelates, and ferrates. The solubility data of Barney (1976) indicate, however, that much higher $(\geq 1 \mathrm{M})$ hydroxide concentrations may be needed in the sludge wash.

\subsubsection{Sodium Nitrate and Sodium Nitrite}

Sodium nitrate and nitrite are the primary oxidants expected in nuclear waste glass melting. Any other alkali metal nitrates and nitrates are expected to behave very similarly and are not explicitly discussed here. The total alkali nitrate and nitrite concentrations should be used to treat the oxidizing capacity of these salts. At adequate temperatures, both nitrate and nitrite are expected to act as strong oxidants that will convert $\mathrm{Fe}, \mathrm{Mn}, \mathrm{Cr}, \mathrm{Ce}$, and $\mathrm{Ni}$ to high oxidation state species. These two compounds, along with $\mathrm{NaOH}$, also provide low melting fluxes in which reactions occur. Sodium nitrate melts at $307^{\circ} \mathrm{C}$, sodium nitrite melts at $271^{\circ} \mathrm{C}$, and $\mathrm{NaOH}$ melts at $318^{\circ} \mathrm{C}$. Sodium nitrate-sodium nitrite eutectic melts at $226^{\circ} \mathrm{C}$, sodium nitrate-sodium hydroxide eutectics melt at $243^{\circ}$ and $251^{\circ} \mathrm{C}$, and sodium nitrite-sodium hydroxide eutectics melt at $232^{\circ}$ and $238^{\circ} \mathrm{C}$ (Voskrensenskaya 1961 , pp. 807-812). In addition, $\mathrm{NaOH}$ binds water strongly, the anhydrous material being produced

(a) Smith, R. A. 1991. Revision of Pretreated Neutralized Current Acid Waste Composition for FY 1991 Pilot Testing. Westinghouse Hanford Company letter to Mr. J. M. Creer, January 21, 1991, Correspondence No. 9150110. 
commercially by drying at temperatures $>400^{\circ} \mathrm{C}$. This strongly held water markedly lowers the melting point, for example, $73 \% \mathrm{NaOH}$ melts at $62^{\circ} \mathrm{C}$, and $80 \% \mathrm{NaOH}$ melts at $140^{\circ} \mathrm{C}$ (Curlin, Bommaraju, and Hansson 1991, pp. 1005-1011). In fact, the boiling point curve for $\mathrm{NaOH}-\mathrm{H}_{2} \mathrm{O}$ remains well above the solubility or crystallization curve for all compositions (Standiford and Badger 1954). Thus, it appears that in heating $\mathrm{NaOH}$-containing melter feeds, some liquid phase will be present at all temperatures. Sodium nitrate and nitrite also provide strong base $\left(\mathrm{Na}_{2} \mathrm{O}\right)$ upon decomposition, as discussed in detail further on.

Sodium nitrate and nitrite are strong oxidants that react rapidly with most reductants at elevated temperatures. With many reductants, in proper proportions, such reactions are explosive and have caused serious accidents. Because of their oxidizing ability and low melting points, sodium or potassium nitrates are widely used as fusion agents, usually in combination with $\mathrm{Na}_{2} \mathrm{CO}_{3}$ or $\mathrm{NaOH}$ or the potassium analogs for the decomposition of refractory samples (such as chromites, sulfides, $\mathrm{Pt}$ metals, and various silicates) for analyses (Sulcek and Povondra, pp. 168, 171-172, and 175).

It can probably be safely concluded that $\mathrm{NaNO}_{3}$ or $\mathrm{NaNO}_{2}$ will react completely and rapidly with most organic compounds at temperatures of $500^{\circ} \mathrm{C}$ or lower. At this temperature, significant decomposition of pure $\mathrm{NaNO}_{3}$ should not occur. The reaction of sodium formate with molten $\mathrm{NaNO}_{3}$ or $\mathrm{NaNO}_{2}$ was reported to be complete in less than $1 \mathrm{~h}$ at $325^{\circ} \mathrm{C}$, and complete reaction with sodium acetate at $325^{\circ} \mathrm{C}$ requires 3 to $6 \mathrm{~h}$ depending on acetate concentration (Kozlowski and Bartholomew 1968). In reactions of $\mathrm{NaNO}_{3}$ and $\mathrm{NaNO}_{2}$ with carbon or organic compounds, $\mathrm{Na}_{2} \mathrm{CO}_{3}$ is the anticipated nonvolatile reaction product. Therefore, when adequate quantities of these reductants are used, all $\mathrm{NaNO}_{3}$ and $\mathrm{NaNO}_{2}$ should be converted to $\mathrm{Na}_{2} \mathrm{CO}_{3}$ (or possibly to organic salts such as sodium oxalate) in the cold cap by the time a temperature of $500^{\circ} \mathrm{C}$ is reached.

When a reductant is not added to the feed and significant amounts of $\mathrm{NaNO}_{3}$ and/or $\mathrm{NaNO}_{2}$ are present, strongly oxidizing conditions will persist in the cold cap to much higher temperatures, regardless of whether the feed was initially acidic or basic. In the case of acidic feeds, however, significant amounts of base will not be present until $\mathrm{NaNO}_{3}$ and $\mathrm{NaNO}_{2}$ decompose to $\mathrm{Na}_{2} \mathrm{O}$.

There is considerable disagreement and uncertainty in the literature on the decomposition of $\mathrm{NaNO}_{3}$ and particularly $\mathrm{NaNO}_{2}$. The very old literature (Quin 1911) indicates that as $\mathrm{NaNO}_{3}$ is heated, it decomposes first to form $\mathrm{NaNO}_{2}$ and then $\mathrm{Na}_{2} \mathrm{O}$ and $\mathrm{Na}_{2} \mathrm{O}_{2}$ at higher temperatures. The decomposition of $\mathrm{NaNO}_{3}$ to $\mathrm{NaNO}_{2}$ as a first step is now generally accepted and is reported (Gordon and Campbell 1955) to begin at about $500^{\circ} \mathrm{C}$.

$$
\mathrm{NaNO}_{3} \leftrightarrows \mathrm{NaNO}_{2}+1 / 2 \mathrm{O}_{2}
$$

Several references present evidence that this reaction is reversible (Bond and Jacobs 1966; Freeman 1956; Sirotkin 1959; Burger et al. 1973, pp. 42-43). Two of these references (Freeman 1956; Sirotkin 1959) give values of the equilibrium constant as a function of temperature for reaction (26), though these are not in agreement. Freeman (1956), as earlier noted by Burger et al. (1973), used more questionable analytical methods and crucible material than did Sirotkin (1959), and indeed, the Burger et al. (1973, p. 42) data agree reasonably well with Sirotkin's. 
The further decomposition of $\mathrm{NaNO}_{2}$ (or of $\mathrm{NaNO}_{2}$ initially present) to sodium oxide or oxides is much less clear, with considerable literature disagreement regarding products and particularly decomposition rates. Freeman (1956) indicated only small amounts of NO were present in the gaseous product, but Burger et al. (1973, pp. 40-41) definitely observed $\mathrm{NO}_{2}$ (visually) when larger (20 g) amounts of $\mathrm{NaNO}_{3}$ were heated to $780^{\circ}$ to $950^{\circ} \mathrm{C}$ in an air atmosphere. This visual observation is presumed to have been the result of oxidation of $\mathrm{NO}$ to $\mathrm{NO}_{2}$ in the cooler zone above the melts. It has been proposed, based on various experimental evidence, that both sodium peroxide and sodium superoxide (Quin 1911; Bond and Jacobs 1966) are formed, at least as reasonably stable intermediates. On the other hand, studies of the thermal stabilities of sodium oxides indicated that sodium superoxide begins to decompose at $120^{\circ} \mathrm{C}$ in $\mathrm{O}_{2}$ or $90^{\circ} \mathrm{C}$ in dry air, forming a series of solid solutions finally reaching $\mathrm{Na}_{2} \mathrm{O}_{3.60}$, decomposing to $\mathrm{Na}_{2} \mathrm{O}_{2}$ at $250^{\circ} \mathrm{C}$ in $\mathrm{O}_{2}\left(215^{\circ} \mathrm{C}\right.$ in air), and this in turn decomposing completely to $\mathrm{Na}_{2} \mathrm{O}$ by $545^{\circ} \mathrm{C}$ (Rode and Golder 1956a, 1956b).

Other work indicates that pure $\mathrm{Na}_{2} \mathrm{O}_{2}$ melts at $675^{\circ} \mathrm{C}$ and experience with its use as a fusion agent (Sulcek and Povondra 1989, pp. 175-176) indicates that it is not completely decomposed until reaching temperatures at least above $700^{\circ} \mathrm{C}$. Burger et al. (1973) found qualitative evidence of significant amounts of $\mathrm{H}_{2} \mathrm{O}_{2}$ in water leaches of the residue from holding $\mathrm{NaNO}_{3}$ at $850^{\circ} \mathrm{C}$ for $4 \mathrm{~h}$, indicating $\mathrm{Na}_{2} \mathrm{O}_{2}$ in the melt. The $\mathrm{NaNO}_{2}$ decomposition will be shown here as:

$$
\begin{gathered}
2 \mathrm{NaNO}_{2} \rightarrow \mathrm{Na}_{2} \mathrm{O}+\mathrm{N}_{2}+3 / 2 \mathrm{O}_{2} \\
2 \mathrm{NaNO}_{2} \rightarrow \mathrm{Na}_{2} \mathrm{O}+2 \mathrm{NO}+1 / 2 \mathrm{O}_{2}
\end{gathered}
$$

Reaction (27) is then assumed to dominate, and sodium peroxide (and less likely the superoxide) may be assumed to be intermediates. It is also considered possible that some of the $\mathrm{NaNO}_{2}$ decomposition produces $\mathrm{N}_{2} \mathrm{O}$ instead of $\mathrm{N}_{2}$ or $\mathrm{NO}$, since certain reducing agents reportedly react with $\mathrm{NaNO}_{2}$ to produce $\mathrm{N}_{2} \mathrm{O}$ (Ray and Ogg 1956; Kozlowski and Bartholomew 1968). Workers have not reported $\mathrm{N}_{2} \mathrm{O}$, however, and in fact Kramer, Munir, and Volponi (1983) in studying the vacuum evaporation of alkali metal nitrates, found that nitrates released only $\mathrm{NO}, \mathrm{N}_{2}$, and $\mathrm{O}_{2}$, and the nitrites released $\mathrm{N}_{2}$ and NO.

Duval (1959a; 1963, p. 200), on the basis of thermogravimetric measurements, found that $\mathrm{NaNO}_{2}$ did not begin to decompose until $750^{\circ} \mathrm{C}$ and that decomposition was not essentially complete until $956^{\circ} \mathrm{C}$. He also noted that these results did not agree with the earlier work of Oswald (1914), who reported decomposition began at only $320^{\circ} \mathrm{C}$, or Ray (1905), who reported oxidation of $\mathrm{NaNO}_{2}$ to $\mathrm{NaNO}_{3}$ at about $500^{\circ} \mathrm{C}$. As noted above, several other references attest to the reversibility of reaction (26) in agreement in principal with Ray's results. Ray reported some decomposition of $\mathrm{NaNO}_{2}$ between the melting point $\left(271^{\circ} \mathrm{C}\right)$ and $500^{\circ} \mathrm{C}$ and reported that $\mathrm{NO}$ dominated over $\mathrm{N}_{2}$ in the gases released in this temperature range.

More recent thermogravimetric work by Bond and Jacobs (1966) on the decomposition rate of $\mathrm{NaNO}_{3}$ to $\mathrm{NaNO}_{2}$ and $\mathrm{NaNO}_{2}$ to $\mathrm{Na}_{2} \mathrm{O}$ indicated that the reaction would be $90 \%$ complete in about $10 \mathrm{~h}$ at $628^{\circ} \mathrm{C}$ or in about $6.3 \mathrm{~h}$ at $649^{\circ} \mathrm{C}$. Using their rate expressions, $90 \%$ completion would be expected in $2.2,0.55,0.37$, and $0.15 \mathrm{~h}$ at $700^{\circ}, 760^{\circ}, 780^{\circ}$, and $850^{\circ} \mathrm{C}$, respectively. 
Burger et al. (1973, pp. 40-44) carried out an experiment in which $20 \mathrm{~g}$ of $\mathrm{NaNO}_{3}$ was heated to $800^{\circ} \mathrm{C}$, held for $0.5 \mathrm{~h}$, further heated to $850^{\circ} \mathrm{C}$, held for $0.5 \mathrm{~h}$, further heated to $900^{\circ} \mathrm{C}$, held for $0.33 \mathrm{~h}$, and further heated to $950^{\circ} \mathrm{C}$. At all temperatures above $780^{\circ} \mathrm{C}, \mathrm{NO}_{2}$ evolution was observed, and at all temperatures above $800^{\circ} \mathrm{C}$, white fume evolution was observed and the total weight loss was greater (by $13 \%$ ) than theoretical for conversion to $\mathrm{Na}_{2} \mathrm{O}$. In another experiment in which $20 \mathrm{~g}$ $\mathrm{NaNO}_{3}$ (in a fused alumina crucible) was placed in a preheated $930^{\circ} \mathrm{C}$ furnace and held at $930^{\circ}$ to $950^{\circ} \mathrm{C}$ for $1 \mathrm{~h}$, only $36 \%$ of the original sodium content remained in the crucible, and $32 \%$ of that had been converted to sodium aluminate while $0.8 \%$ remained as $\mathrm{NaNO}_{3}$ (based on water leachate analysis).

These experiments show that not only is $\mathrm{NaNO}_{2}$ decomposition much slower and/or less complete at given temperatures than indicated by Bond and Jacobs (1966) and several older references, but that $\mathrm{NaNO}_{3}$ and/or $\mathrm{NaNO}_{2}$ are appreciably volatile before decomposition occurs. Further studies by Burger et al. (1973, pp. 46-50) fully confirmed the volatility at temperatures as low as $650^{\circ} \mathrm{C}$. This volatility, unrecognized in earlier research, serves as a major explanation of the lack of agreement between various studies (particularly thermogravimetric) of $\mathrm{NaNO}_{3}$ and $\mathrm{NaNO}_{2}$ decomposition. Even more recent work (Kramer, Munir, and Volponi 1982, 1983) in which the volatility of $\mathrm{NaNO}_{3}$ and $\mathrm{NaNO}_{2}$ was recognized, reports low decomposition temperatures relative to those found by Duval and Burger et al. Other factors include possible effects of various crucible materials, possible impurities in the salts that might catalyze their decomposition, and, especially with the very old work, possible reducing impurities (organics) in the salts.

Sugiyama and Takahashi (1967b) studied the effect of various metal oxides on $\mathrm{NaNO}_{3}$ and $\mathrm{NaNO}_{2}$ decomposition. They reported significantly changed gas ratios (greater yield of NO) and lower decomposition temperatures with very small amounts of $\mathrm{V}_{2} \mathrm{O}_{5}, \mathrm{NiO}, \mathrm{ZnO}, \mathrm{CoO}$, or $\mathrm{MgO}$. They, as well as Hoshino, Utsunomiya, and Abe (1981), also studied the effect of other added oxides on reaction temperatures and gas yields including those of $\mathrm{Si}, \mathrm{Al}, \mathrm{Ti}, \mathrm{Mg}, \mathrm{Zr}$, and $\mathrm{Mn}$.

Burger et al. (1973, pp. 41-44) carried out further experiments in deep covered crucibles that extended out of the furnace hot zone to allow reflux of the volatilized salts back into the hot zone, again with $20 \mathrm{-g}$ batch sizes, and chemical analyses of water leachates of the total crucible contents for nitrate and nitrite. In experiments starting with $\mathrm{NaNO}_{3}$, at $700^{\circ} \mathrm{C}, 96 \%$ of the original combined $\mathrm{N}$ remained after $17.8 \mathrm{~h}$; at $775^{\circ} \mathrm{C}, 95 \%$ of the original $\mathrm{N}$ remained after $2 \mathrm{~h}$; and at $850^{\circ} \mathrm{C}, 28.5 \%$ of the original $\mathrm{N}$ remained after $1.75 \mathrm{~h}$ and $7.1 \%$ remained after $4 \mathrm{~h}$. Also, the nitrite-to-nitrate ratio in the final cooled melt increased with temperature between $700^{\circ}$ and $775^{\circ} \mathrm{C}$ in agreement with Sirotkin's (1959) data, but at higher temperatures, the ratio decreased with both temperature and time. After $4 \mathrm{~h}$ at $850^{\circ} \mathrm{C}, 7 \%$ of the $\mathrm{N}$ remained in the frozen melt, all as nitrate regardless of whether the starting material was $\mathrm{NaNO}_{2}$ or $\mathrm{NaNO}_{3}$. This puzzling behavior indicated that either formed peroxide (which could be detected qualitatively in the aqueous leaches and by gas evolution during the aqueous leaching process), reoxidized nitrite to nitrate on melt cooling, or that thermally stable, poorly defined species such as ortho- or pyronitrates (Shams El Din and Hosary 1967a, 1967b; Kohlmuller 1959) or peroxynitrates are formed at high temperatures and revert to (metal) nitrate on melt cooling. In any case, the decompositions of pure $\mathrm{NaNO}_{3}$ and $\mathrm{NaNO}_{2}$ are apparently complex, are neither well defined nor understood in the literature, and most importantly do not occur at a significant rate (in terms of cold-cap lifetimes) until temperatures reach the range of $850^{\circ}$ to $950^{\circ} \mathrm{C}$.

The high temperatures of $\mathrm{NaNO}_{3}$ and $\mathrm{NaNO}_{2}$ decomposition are important in waste glass redox chemistry because reactions (27) and (28) provide the only source of strong base, other than that ini- 
tially present in the feed, to drive the oxidation reactions forming chromate, manganate, ferrate, and nickelate. On the other hand, at these temperatures, glassmaking is in full progress with the formed $\mathrm{Na}_{2} \mathrm{O}$ rapidly attacking silica and other materials such as $\mathrm{Al}_{2} \mathrm{O}_{3}$. In fact, Burger et al. (1973) found that in $4 \mathrm{~h}$ at $850^{\circ} \mathrm{C}$, over $16 \%$ of the $\mathrm{Na}_{2} \mathrm{O}$ that formed had reacted with the low surface area fused alumina crucible. The lowest melting eutectic in the $\mathrm{Na}_{2} \mathrm{O}-\mathrm{SiO}_{2}$ system occurs at $790^{\circ} \mathrm{C}$, and the main glass-forming reactions (using the more stable and higher melting point $\mathrm{Na}_{2} \mathrm{CO}_{3}$ ) in commercial sodalime glass take place between $700^{\circ}$ and $900^{\circ} \mathrm{C}$ (Volf $1984, \mathrm{pp} .232$ ). Since both boron and lithium tend to lower these temperatures further (Volf 1984), it seems very likely that in nuclear waste glass formulations the $\mathrm{Na}_{2} \mathrm{O}$ formed by $\mathrm{NaNO}_{3}-\mathrm{NaNO}_{2}$ decomposition will have limited availability for promoting formation of higher oxidation state metal ions, such as chromate and manganate. For glassmelter feeds originally containing nitric acid, decomposition of $\mathrm{NaNO}_{3}-\mathrm{NaNO}_{2}$ (and other alkali nitrate) is the only source of strong base. Because of this limited availability of strong base, metal ions ( $\mathrm{Fe}, \mathrm{Cr}, \mathrm{Mn}, \mathrm{Ni}$ ) in acidic feeds are expected not to be as highly oxidized in the cold cap as when processing initially alkaline feeds. Also, with alkaline feeds initially containing nitrite, reaction (16) allows oxidation without significant excess base.

\subsubsection{Sulfate}

Sulfate is discussed briefly because it is a potential oxidizing agent found in nuclear waste glass feeds. It was noted earlier in this report that sulfate affects foaming because it lowers glass surface tension (Volf 1984, p. 848). Sulfate undergoes the following reactions:

$$
\begin{aligned}
& 2 \mathrm{Na}_{2} \mathrm{SO}_{4} \rightarrow 2 \mathrm{Na}_{2} \mathrm{O}+2 \mathrm{SO}_{2}+\mathrm{O}_{2} \\
& \mathrm{Na}_{2} \mathrm{SO}_{4}+4 \mathrm{CO} \rightarrow \mathrm{Na}_{2} \mathrm{~S}+4 \mathrm{CO}_{2} \\
& \mathrm{Na}_{2} \mathrm{SO}_{4}+4 \mathrm{H}_{2} \rightarrow \mathrm{Na}_{2} \mathrm{~S}+4 \mathrm{H}_{2} \mathrm{O}
\end{aligned}
$$

Reaction (29) does not proceed below about $1200^{\circ} \mathrm{C}$ and is most efficient at about $1450^{\circ} \mathrm{C}$ (Volf 1984 , pp. 534-526). In this regard, $\mathrm{Na}_{2} \mathrm{SO}_{4}$ is used to refine glass in the $1200^{\circ}$ to $1450^{\circ} \mathrm{C}$ range. On this basis, it appears that $\mathrm{Na}_{2} \mathrm{SO}_{4}$ should not release $\mathrm{O}_{2}$ via reaction (29) in nuclear waste glasses at $1150^{\circ} \mathrm{C}$.

Reactions (30) and (31) occur in commercial gas-fired melters at lower temperatures than reaction (29) and result in loss of sulfate as a refining agent. Volf (1984) stated that, "Addition of carbon as a reducing agent to small amounts of sulfate on refining is to no avail and sometimes even harmful, because the loss of gaseous $\mathrm{SO}_{2}$ will take place ineffectively in the first stages of melting at lower temperatures ..." These sulfate reductions may have two effects in nuclear waste glass melting if adequate reductant is used. The first is to destroy the foam-breaking capability of $\mathrm{Na}_{2} \mathrm{SO}_{4}$ in the glassforming temperature regime. The second is to produce (with over reduction depending on the amount of reductant used relative to other oxidants than sulfate) $\mathrm{Na}_{2} \mathrm{~S}$ leading to precipitation of sulfides of metals such as $\mathrm{Ni}$. 


\subsection{Reducing Agents Present in or Added to Melter Feed}

As discussed in the Introduction, various researchers have concluded that the extent of foaming problems in liquid-fed ceramic melters are determined by the extent of oxygen release from decomposition of higher oxidation state oxides of multioxidation state metals. Although this conclusion may (or may not) be correct, the prior work does not constitute adequate proof that it is correct. Some of this work was based on the maximum height of expansion produced when glass feed batches (calcined simulated waste plus frit) were heated in 16- or 25-g batches in laboratory crucibles in air (Blair and Lukacs 1980). In some of these experiments, $\mathrm{FeO}$ and/or $\mathrm{MnO}$ was substituted for $\mathrm{Fe}_{2} \mathrm{O}_{3}$ and/or $\mathrm{MnO}_{2}$, and in others various carbonaceous or other reducing agents were added. As noted earlier, the experiments with $\mathrm{FeO}$ and $\mathrm{MnO}$ should not have been meaningful since these oxides are expected to oxidize in air at temperatures well below glass forming. In addition, review of this work indicates a maximum difference of $65 \%$ in foam height between runs with or without reduced components or reducing agents versus up to $47 \%$ variation in height in the much more limited number of duplicate runs for feeds of exactly the same composition. In several cases, runs with reducing agents produced greater foam height than controls without reductants. It is concluded that Blair and Lukacs (1980) provided no proof whatsoever either that $\mathrm{Mn}$ is the cause of serious foaming in nuclear waste glass melters or that reductants will have a beneficial effect on melter foaming.

Note that Blair and Lukacs (1980) assumed, by the very nature of their experimental design, that the foaming problem in the liquid-fed melters is directly related to the maximum total expansion (foam) height that resulted from heating the batch from $25^{\circ} \mathrm{C}$, through the melting point, and on to $1050^{\circ} \mathrm{C}$. The author tends to agree with this assumption because two things happen when reaction goes beyond sintering to the point of sufficient melting to produce a continuous liquid phase that closes off porosity. First, significant gas must evolve from reaction of $\mathrm{NaNO}_{3}, \mathrm{NaNO}_{2}$, and $\mathrm{Na}_{2} \mathrm{CO}_{3}$ with glass formers or frit components to produce borates and silicates of the sodium. Additionally, manganates, ferrates and nickelates, if formed at lower temperatures, will also decompose when reacting with $\mathrm{SiO}_{2}$ and $\mathrm{B}_{2} \mathrm{O}_{3}$ in frit or glass formers as homogenization occurs. Second, along with melting and homogenization, maximum viscosity occurs at the lowest temperature at which the glass forms, and this viscosity will decrease rapidly with temperature increase.

Because of these two factors, most of the melter foam would likely form in this temperature regime of about $700^{\circ}$ to $800^{\circ} \mathrm{C}$. This temperature regime would correspond to the bottom edge of the cold cap in the melter. The admittedly larger volume of the melter where molten glass exists at or near $1150^{\circ}$ and relatively low viscosity probably contribute much less to foaming. The conclusion of maximum foaming at $\sim 700^{\circ} \mathrm{C}$ was also reached by Bickford, Diemer, and Iverson (1986) based on experimental studies in which maximum foaming was reported at about $700^{\circ} \mathrm{C}$ for formated, elemental carbon-containing batches.

Lucktong and Hrma (1988) studied the effect of adding large amounts (up to 8\%) of $\mathrm{Mn}_{3} \mathrm{O}_{4}$ (which they reported to be stable as a pure compound in air from $870^{\circ}$ to about $1730^{\circ} \mathrm{C}$ ) to borosilicate glass. They reported a rather narrow foaming range that peaked at about $900^{\circ} \mathrm{C}$ when temperature was raised rapidly. This indicated that foaming caused by $\mathrm{O}_{2}$ release from $\mathrm{Mn}_{3} \mathrm{O}_{4}$ occurs well above the $700^{\circ} \mathrm{C}$ range observed for simulated waste by Bickford, Diemer, and Iverson (1986), who also observed rapid foam collapse at $950^{\circ} \mathrm{C}$. Experimental work now being performed at PNL indicates that both formated and unformated (alkaline) simulated Hanford NCAW wastes foam as melt consolidation occurs at $\sim 700^{\circ} \mathrm{C}$, and foam collapse occurs well before $900^{\circ} \mathrm{C}$. On the other hand, Goldman, Brite, and 
Richey (1986), again by the nature of their experimental design (the measurement at $1150^{\circ} \mathrm{C}$ of reboil pressure of glass made in the melters at $1150^{\circ} \mathrm{C}$ ), have made the implicit assumption that the glassfoaming problems in the melter result from rapid $\mathrm{O}_{2}$ release from high oxidation state species throughout the entire melter at $\sim 1150^{\circ} \mathrm{C}$ when a temperature increase occurs with power increase. Their assumption is strongly questioned, along with their conclusion that reboil pressure is a good measure of melter foaming. One basis for questioning their conclusions was the fact that they found the oxidant level (apparent percent of $\mathrm{Ce}^{4+}$ ) of half their Hanford CAW glass samples was about as high as in their NCAW glass samples, whereas the CAW glass produced the lowest and the NCAW glass almost the highest foaming of all glasses reported. In addition, note that the total initial nitrate level of the nonfoaming CAW was 260 times that of NCAW feed, and the higher temperature decomposing alkali nitrate level in CAW feed was 345 times that in the NCAW feed. Also, as noted earlier, the determined oxidant levels in both their CAW and NCAW glasses (Goldman, Brite, and Richey 1986) appeared very near the $1150^{\circ} \mathrm{C}$ equilibrium values for waste borosilicate glasses that would be predicted from Schreiber's data (1984) for atmospheric pressure air. The differences between their various samples appear to be best explained by temperature variations in the melter from which the glass was quenched.

On the basis of these studies (and some others of similar rigor), and on the presumption derived from them that $\mathrm{O}_{2}$ release is the principal cause of foaming, addition of reducing agents has been recommended to decrease foaming in melter runs (Blair and Lukacs 1980; Goldman, Brite, and Richey 1986; Bickford and Diemer 1986; Bickford, Diemer, and Iverson 1986; Bickford et al. 1990; Bickford, Hrma, Bowen 1990), and analytical methods have been developed to control redox levels in glass (Goldman and Brite 1986; Goldman 1985; Brock 1990). Most glass melter runs in recent years have included adding reductants such as carbon, sugar, cornstarch, formic acid, or combinations of these to the melter feeds. Unfortunately, many other changes have been made to melter feeds, equipment, and melter operation during this time frame, so it is difficult to review run performance to determine the effect of adding reductants.

Using formic acid as a reductant in nuclear waste glass melting is based on its proposed use as a reducing agent by Savannah River Plant to remove $\mathrm{Hg}$ from their waste (Bickford et al. 1992). This use was then extended to its use to improve feed rheology, and finally with almost no good evidence of its effectiveness, into glass redox adjustment to minimize melter foaming. There has been significant pressure to use it for this purpose at Hanford as well. Because formic acid undergoes redox reactions with nuclear waste components in the aqueous solution before melter feeding, considerable studies of these reactions have been performed (Ritter, Zamecnik, and Hsu 1992). ${ }^{(a, b, c)}$ More effort has been

(a) Wiemers, K. D., C. A. Anderson, and M. E. Peterson. 1987. Evaluation of Process Off-Gases Released During the Formating of an HWVP Feed Simulant. HWVP-87-V110203G, Pacific Northwest Laboratory, Richland, Washington.

(b) Wiemers, K. D., M. H. Langowski, and M. R. Powell. 1991. Detailed Design Data Package. PHTD-91-03.02-X898, Pacific Northwest Laboratory, Richland, Washington.

(c) King, R. B., A. D. King, Jr., N. K. Bhuttacharyya, G. Vemparla, A. Vemparla, N. B. Turner, and J. L. Walters. 1993. Hanford Waste Vitrification Plant Hydrogen Generation Study. PHTDK0959, prepared for Pacific Northwest Laboratory, Richland, Washington. 
spent studying formate treatment of melter feeds than on studying the properties of other reductants or other rheology modifiers in melter feeds. In addition to the intentionally added reductants, many Hanford and Savannah River Plant waste tanks contain significant amounts of a variety of organic materials and cyanide compounds. To the extent that these remain in melter feeds, they will also act as reductants in the melters. The chemistry of some of these reductants is discussed in the following subsections.

\subsubsection{Formic Acid and Formates}

The following reactions have been reported for formic acid and sodium formate and for their decomposition products:

$$
\begin{aligned}
& \mathrm{HCOOH} \rightarrow \mathrm{H}_{2} \mathrm{O}+\mathrm{CO} \\
& \mathrm{HCOOH} \rightarrow \mathrm{H}_{2}+\mathrm{CO}_{2} \\
& 2 \mathrm{HCOOH} \rightarrow \mathrm{H}_{2} \mathrm{O}+\mathrm{CO}_{2}+\mathrm{H}_{2} \mathrm{CO} \\
& \mathrm{NO}_{2}^{-}+\mathrm{HCOOH} \rightarrow \mathrm{HNO}_{2}+\mathrm{HCOO}^{-} \\
& 2 \mathrm{NO}_{2}^{-}+4 \mathrm{HCOOH} \rightarrow \mathrm{N}_{2} \mathrm{O}+\mathrm{CO}_{2}+3 \mathrm{H}_{2} \mathrm{O}+2 \mathrm{HCOO}^{-} \\
& 2 \mathrm{NO}_{3}^{-}+6 \mathrm{HCOOH} \rightarrow \mathrm{N}_{2} \mathrm{O}+4 \mathrm{CO}_{2}+5 \mathrm{H}_{2} \mathrm{O}+2 \mathrm{HCOO}^{-} \\
& \mathrm{NaCOOH} \rightarrow \mathrm{NaOH}+\mathrm{CO} \\
& \mathrm{NaCOOH}+\mathrm{NaOH} \rightarrow \mathrm{Na}_{2} \mathrm{CO}_{3}+\mathrm{H}_{2} \\
& 2 \mathrm{NaCOOH} \rightarrow \mathrm{Na}_{2} \mathrm{C}_{2} \mathrm{O}_{4}+\mathrm{H}_{2} \\
& \mathrm{Na}_{2} \mathrm{C}_{2} \mathrm{O}_{4} \rightarrow \mathrm{Na}_{2} \mathrm{CO}_{3}+\mathrm{CO} \\
& 2 \mathrm{NaCOOH} \rightarrow \mathrm{Na}_{2} \mathrm{CO}_{3}+\mathrm{CO}+\mathrm{H}_{2}
\end{aligned}
$$




$$
\begin{gathered}
\mathrm{NaCOOH}+\mathrm{NaNO}_{3} \rightarrow \mathrm{NaNO}_{2}+1 / 2 \mathrm{Na}_{2} \mathrm{CO}_{3}+1 / 2 \mathrm{H}_{2} \mathrm{O}+1 / 2 \mathrm{CO}_{2} \\
\mathrm{NaCOOH}+\mathrm{NaNO}_{2} \rightarrow \mathrm{Na}_{2} \mathrm{CO}_{3}+1 / 2 \mathrm{~N}_{2} \mathrm{O}+1 / 2 \mathrm{H}_{2} \mathrm{O}
\end{gathered}
$$

Reactions (32 through 34) are three different spontaneous decomposition routes of formic acid that occur in formic acid itself or in aqueous solutions (Pernert 1952, pp. 665-666; Gibson 1969; Thorpe and Whiteley 1947, p. 324). The relative contributions of these three reactions, as well as the rates, depend on various factors including temperature and particularly catalysis by various materials such as metal oxides, metal ions in solution, and acids. The decomposition via reaction (33) is observed in formating simulated nuclear waste glass aqueous feed slurry (Ritter, Zamecnik, and Hsu 1992). ${ }^{(a, b)}$ The hydrogen produced by reaction (33) requires adequate controls to avoid explosive levels of $\mathrm{H}_{2}$ in the plant. In this regard, note that $\mathrm{N}_{2} \mathrm{O}$ (and possibly $\mathrm{NO}$ ), which is also formed in aqueous formating mixtures, ${ }^{(a, b)}$ markedly lowers the hydrogen-oxygen ignition temperature (Bailar et al. 1973b, pp. 321-322). Because of the decomposition that occurs in reaction (32), temperature control and adequate ventilation are required to store large quantities of formic acid because of the health hazard of $\mathrm{CO}$.

Reaction (35) is the simple acidification of nitrites in aqueous solution to produce nitrous acid, a very weak and unstable acid that decomposes to NO and nitric acid. The net result is the conversion of three moles of nitrite and two moles of formic acid to two moles of $\mathrm{NO}$, one mole of $\mathrm{NO}_{3}^{-}$, and two moles of formate ion. Reaction (36) is the aqueous phase reduction of nitrite by formic acid to produce $\mathrm{N}_{2} \mathrm{O}$. If sufficient formic acid is added to acidify waste slurry, nitrite should be completely destroyed through reactions (35) and (36).

King et al: (b) studied the reaction of simulated waste feeds with formic acid. They measured gas production versus time during formate treatment of the aqueous waste slurry at $-90^{\circ} \mathrm{C}$ with and without noble metals and other waste constituents. The noble metals $\mathrm{Rh}, \mathrm{Pd}$, and $\mathrm{Ru}$ (expected as fission products) catalyzed reaction (33) markedly with detectable $\mathrm{H}_{2}$ being produced only in their presence. The noble metals were more effective when added as solution than as metallic catalysts. The behaviors of these systems were very complex with other materials such as nitrite, $\mathrm{Fe}$, and $\mathrm{Al}$ increasing (or with some noble metals decreasing) the catalytic effect on reaction (33). They found that Pd also catalyzed reaction (36) and that in the absence of nitrite, some nitrate was reduced by formate in the presence of Pd (reaction 37). In addition to these reactions, some reduction of the nitrogen species (present or formed as intermediates) to ammonia was observed.

The net effect of 1) the catalyzed decomposition of formic acid, 2) the catalyst-controlled variable routes in the reaction of formic acid with nitrite (and to a lesser extent with nitrate), and 3) the effect of

(a) Wiemers, K. D., C. A. Anderson, and M. E. Peterson. 1987. Evaluation of Process Off-Gases Released During the Formating of an HWVP Feed Simulant. HWVP-87-V110203G, Pacific Northwest Laboratory, Richland, Washington.

(b) King, R. B., A. D. King, Jr., N. K. Bhuttacharyya, G. Vemparla, A. Vemparla, N. B. Turner, and J. L. Walters. 1993. Hanford Waste Vitrification Plant Hydrogen Generation Study. PHTD-K0959, prepared for Pacific Northwest Laboratory, Richland, Washington. 
promoters or inhibitors ( $\mathrm{Fe}, \mathrm{Al}$, etc.) that change catalyst efficiency is that it would appear to be very difficult to predict the amount of formate remaining in the aqueous slurry at the end of the aqueous reactions. This remaining formate is needed to reduce residual nitrate in the melter to produce a glass with any significant amount of $\mathrm{Fe}(\mathrm{II})$.

It has been stated (Pernert 1952, p. 665) that hydrogen, carbon monoxide, sodium oxalate, and sodium carbonate are all always found in the thermal decomposition of sodium formate and that other products may form. Reactions (38) and (39) are two steps of one route in the thermal decomposition of sodium formate. The sum of these two steps is the net reaction (42). Reactions (40) and (41) are two steps in a second route in the thermal decomposition of sodium formate. Although the sum of these two steps results in the same net reaction (42), the implications of these two routes can be significantly different. Sodium formate melts at $253^{\circ} \mathrm{C}$, and slow decomposition to sodium carbonate via reactions (38) and (39) occurs at $300^{\circ} \mathrm{C}$ (Pernert 1952, p. 666). With one mole or more of hydroxide per mole of sodium formate initially present, reaction (39) begins at $210^{\circ} \mathrm{C}$ and proceeds smoothly at $250^{\circ} \mathrm{C}$ (Thorpe and Whiteley 1947, p. 325 ). This means that sodium formate decomposition may occur at a temperature as low as $250^{\circ} \mathrm{C}$ if adequate hydroxide is present and at $\geq 300^{\circ} \mathrm{C}$ otherwise, and that either $\mathrm{H}_{2}$ or $\mathrm{H}_{2}$ and $\mathrm{CO}$ will be products of this decomposition. Small amounts of hydroxide apparently catalyze the formation of sodium oxalate, reaction (40), (Thorpe and Whiteley 1947, p. 325; Pernert 1952, p. 666).

Only at higher temperatures does the decomposition to sodium oxalate and hydrogen via reaction (40) proceed at reasonable rates. At $380^{\circ} \mathrm{C}$ or higher, a vigorous exothermic reaction produces sodium oxalate and hydrogen in high yields, this process is used to commercially produce oxalic acid (Pernert 1952 , p. 666). Only above about $440^{\circ}$ or $450^{\circ} \mathrm{C}$ does reaction (41) begin in which sodium oxalate decomposes to sodium carbonate and carbon monoxide (Pernert 1952, p. 666; Duval 1963, p. 210). The significance of the difference in these two routes of sodium formate decomposition is that through reaction (40) (sodium oxalate formation) the reducing agent in the glassmaking process could be maintained in the cold cap to higher temperature than possible if decomposition occurred by reactions (38) and (39). It is conceivable, of course, that unidentified, active, short-lived intermediates in such a decomposition to oxalate may immediately react with nitrate. The relative amounts of sodium formate going through these two routes will depend on the heating rate since the oxalate route is favored by higher temperature. It will also depend on catalytic effects of other components including calcium salts, which catalyze direct decomposition to carbonates (Pernert 1952, p. 666).

Other work has indicated that small amounts of other materials form during the sodium formate decomposition or during the decomposition of the intermediate, sodium oxalate. Thus, Shishido and Masuda (1973) reported production of $\mathrm{CH}_{4}, \mathrm{HCHO}, \mathrm{HCO}_{2} \mathrm{Me}$, and $\mathrm{MeOH}$ and concluded that the compounds were produced by secondary reactions of $\mathrm{H}_{2}, \mathrm{CO}$, and $\mathrm{CO}_{2}$ on catalytic oxide and carbonate surfaces remaining. Duval $(1963$, p. 210$)$ reported that the $\mathrm{Na}_{2} \mathrm{CO}_{3}$ resulting from decomposition of sodium oxalate, reaction (41), "often is contaminated with carbon, coming from the decomposition of carbon monoxide." Shishido and Masuda (1976) reported that when amorphous carbon is formed in the decomposition of alkali formates, it tends to prevent the conversion to oxalate. Note that at the temperatures where sodium oxalate and sodium formate decompose reasonably rapidly $\left(500^{\circ} \mathrm{C}\right.$ and $300^{\circ}$ to $350^{\circ} \mathrm{C}$, respectively), significant disproportionation of $\mathrm{CO}$ to carbon and $\mathrm{CO}_{2}$ is expected thermodynamically, but rates are very low unless catalysts such as $\mathrm{Fe}$ or $\mathrm{Ni}$ along with their oxides or graphite as a promoter are present (Bailar et al. 1973a, pp. 1196-1197). Bickford, Hrma, and Bowen (1990) found significant amounts of graphite in formated simulated waste glass feed mixtures that had been held $4 \mathrm{~h}$ at $400^{\circ} \mathrm{C}$, even with a sample that was under-reduced with regard to forming $\mathrm{CO}_{2}$ and 
either $\mathrm{N}_{2} \mathrm{O}$ or $\mathrm{NO}$ from the contained $\mathrm{NaNO}_{3}$. They found, as expected, even larger amounts of graphite when the waste mixture contained sucrose. Shishido and Masuda (1971) also reported that metal ions such as $\mathrm{Co}, \mathrm{Ni}$, and $\mathrm{Cu}$ markedly catalyzed the decomposition of alkali formates to carbonates, reactions (38) and (39) rather than through oxalate. Meisel and Halmos (1971) studied the thermal decomposition of the $C_{1}$ to $C_{4}$ monobasic and the $C_{2}$ to $C_{10}$ dibasic carboxylic acids (78) and Meisel et al. (1975) studied the effects of variables on the relative amounts of oxalate or carbonate formed in the decomposition of alkali formates.

Reactions (43) and (44) constitute the two-step reduction of sodium nitrate by sodium formate (Kozlowski and Bartholomew 1968). The sodium nitrate is reduced in a first step to sodium nitrite, and then in a second step the formed sodium nitrite reacts with further sodium formate to entirely convert the two sodium salts to sodium carbonate. These studies were performed with a large excess of sodium nitrate or sodium nitrite over stoichiometric since near-stoichiometric mixtures are explosive. Whether $\mathrm{N}_{2} \mathrm{O}$ would be the sole nitrogen-containing product under other conditions, including possible catalyst materials in the waste slurries, is uncertain. These reactions are reportedly complete in less than $1 \mathrm{~h}$ at $325^{\circ} \mathrm{C}$ (the corresponding reactions with sodium acetate required 3 to $6 \mathrm{~h}$ at $325^{\circ} \mathrm{C}$ ).

Although actual kinetic data for reactions (38) through (44) were not found and various waste components may catalyze these reactions as well, it is important to note that the quantitative or semiquantitative data indicate that sodium formate decomposes at a significant rate in the same temperature range (about $300^{\circ}$ to $375^{\circ} \mathrm{C}$ ) as that in which it reacts in the molten state with sodium nitrate and nitrite. Thus, release of $\mathrm{H}_{2}$ and $\mathrm{CO}$ in this temperature range is expected, and since these reducing gases escape readily, the efficiency of nitrate and particularly $\mathrm{Fe}_{2} \mathrm{O}_{3}$ reduction is probably low. It also appears probable that sodium formate, although molten at only $300^{\circ}$ to $350^{\circ} \mathrm{C}$, will not reduce $\mathrm{Fe}_{2} \mathrm{O}_{3}$ in this temperature range. Thus, in the full-scale liquid-fed melter, any $\mathrm{Fe}_{2} \mathrm{O}_{3}$ reduction is likely to occur by $\mathrm{H}_{2}$ and/or $\mathrm{CO}$, or by small amounts of pyrolytic carbon. This would no doubt occur in a hotter zone of the cold cap or melt than where these reductants are formed.

Bickford, Diemer, and Iverson (1986) also noted that in laboratory crucible melts containing formate salts and carbon, $\mathrm{Fe}$ (III) reduction to $\mathrm{Fe}$ (II) did not occur until about $950^{\circ} \mathrm{C}$ where the reducing agent was undoubtedly pyrolytic carbon. Bickford did not publish experimental details, and their feed mixes may have contained tetraphenyl boron as well, but it seems unlikely that the decomposition of formate itself would consistently produce enough pyrolytic carbon to reduce much Fe(III). The carbon oxidation state in formate is the same as that in CO and, as noted earlier, formation of any pyrolytic carbon can be considered the result of disproportionation of carbon monoxide.

If $\mathrm{Fe}$ (III) reduction is accomplished by $\mathrm{H}_{2}$ and/or $\mathrm{CO}$, it would mean that reduction efficiency would be influenced by size and design of equipment, size of cold cap, and melter gas sweep rate. In particular, small-scale laboratory experiments might not simulate the behavior of the full-scale melters well at all. If reduction is by pyrolytic carbon, reduction efficiencies would be very low. Calculations based on laboratory experimental data published by Farnsworth ${ }^{(a)}$ indicate efficiencies as low as $15 \%$ for reduction of nitrate via reactions (43) and (44) and reduction of $\mathrm{Fe}$ (III) to $\mathrm{Fe}$ (II).

(a) Farnsworth, R. K. 1987. The Effect of Feed Composition and Formic Acid Addition on Glass Redox State. HWVP-87-V110203A, Pacific Northwest Laboratory, Richland, Washington. 


\subsubsection{Other Reductants}

A tremendous variety of reducing agents may be used to control the oxidation state of glass, including metallic or semimetallic elements (such as powdered iron, aluminum, silicon), carbon in its elemental or near elemental forms (coke, coal, or graphite), and an almost infinite variety of organic compounds. Regarding the redox state of the final glass, there may be little difference between these reducing agents when compared on the basis of equivalents of reducing capacity. Other reducing agents (such as formic acid discussed in the preceding section) may decompose into volatile reducing gases at temperatures at or below those where reduction of the glass-feed oxidants occurs. These reducing gases would escape unreacted in quantities that vary and are difficult to predict.

In addition to controlling the final oxidation state of glass, there are many other factors that may be important in choosing a reductant to control glass foaming, though the importance of these factors ranges from poorly proven to not proven at all. For example, it is unclear whether the redox state of final glass, held at $1150^{\circ} \mathrm{C}$, is an adequate measure of foaming that may occur at lower temperatures during glass formation. Hypothetically, it might be possible to add solid coke as a reductant, and the kinetics of the solid-liquid reactions might be such that little of the coke (depending on its particle size) would react in the cold cap or in the glass-forming region where foaming might occur. After most of the oxidizing species (nitrate, nitrite, ferrates, manganates, etc.) decompose, the coke might gradually reduce $\mathrm{Fe}(\mathrm{III})$ in the longer melter holdup at $1150^{\circ} \mathrm{C}$.

When choosing a reductant, cost, toxicity, possible effects on final glass properties, and ease of handling and addition to the cold-cap feed are important considerations. One of the claimed advantages of formic acid is its ability to improve feed slurry rheology, presumably by dissolving some of the hydrous oxides present in alkaline wastes. On this basis, the value of other organic acids might be related to their acid strengths. The use of an acidic reductant will cause conversion of nitrites to unstable nitrous acid [reaction (35)], which decomposes and leaves behind the metal salts of the acidic reductant. This destruction of nitrite prevents reactions such as (16) from occurring at low temperature and lowers the total oxidant capacity of the melter feed. Some potential glass reductants [including formic acid, reaction (36)] act as reductants in the aqueous phase, reducing nitrite, and under some conditions, reducing $\mathrm{NO}_{3}^{-}$to a certain extent as well [reaction (37)]. Such aqueous phase reactions do not appear to be advantageous. Since these reactions do not have the same stoichiometry as the simple acidification and decomposition of $\mathrm{HNO}_{2}$, and because their relative contributions vary with conditions, the unpredictable efficiency is a very negative aspect of such reductants.

The volatility of organic compounds is important in determining whether they can be used as reductants. In most cases, nonacidic low-boiling organics can be expected to boil away before reaching a temperature in the cold cap at which they will reduce the oxidizing glass components such as nitrate, nitrite, and higher oxidation state metals. With volatile organic acids, the reactions with hydroxide, carbonate, or nitrites, and in some cases with nitrate through reactions similar to (35),(36), and (37), will prevent volatilization. Note, though, that in wastes high in alkali nitrates but low in carbonate, hydroxide, and nitrite, too little of the volatile organic acid reductant may remain in the mixture to counteract the oxidizing capacity of the nitrate.

The average oxidation state of carbon in carbonaceous reductants may be very important. First, if the decomposition of the reductant (or the salts of the reductant in the case of organic acids) occurs at low temperatures relative to the temperature of reaction with the cold-cap oxidants [as with formate, 
reactions (38) and (39) and to a lesser extent (41) versus reactions (43) and (44)], reductant may be lost from the system as potentially reducing gases. If the carbon in the added reductant is in a highly oxidized form, such as in formate (carbon +2 ) where the carbon state is the same as in CO, no elemental carbon will remain in the mixture except that resulting from $\mathrm{CO}$ disproportionation. This has the marked disadvantage of low (and difficult to predict) reduction efficiency by formate depending on the extent of reduction in the cold cap by $\mathrm{CO}$ and $\mathrm{H}_{2}$. On the other hand, a large excess of formate in the waste feed will leave little residual graphite in the final glass.

If the carbon in the reductant is in a more reduced form such as in acetate (carbon in the 0 oxidation state), there is a greater probability of producing elemental carbon. Indeed, pyrolysis of most complex organic materials in the absence of air produces some carbon. Decomposition of sodium acetate without carbon oxidation state disproportionation is shown in reaction (45) below:

$$
\begin{gathered}
\mathrm{NaC}_{2} \mathrm{H}_{3} \mathrm{O}_{2} \rightarrow \mathrm{NaOH}+2 \mathrm{C}+\mathrm{H}_{2} \mathrm{O} \\
\mathrm{NaC}_{2} \mathrm{H}_{3} \mathrm{O}_{2}+\mathrm{H}_{2} \mathrm{O} \rightarrow \mathrm{NaHCO}_{3}+\mathrm{CH}_{4} \\
6 \mathrm{NaC}_{2} \mathrm{H}_{3} \mathrm{O}_{2} \rightarrow 3 \mathrm{Na}_{2} \mathrm{CO}_{3}+\mathrm{CO}_{2}+4 \mathrm{C}_{2} \mathrm{H}_{4}+\mathrm{H}_{2} \mathrm{O} \\
\mathrm{NaC}_{2} \mathrm{H}_{3} \mathrm{O}_{2}+\mathrm{NaOH} \rightarrow \mathrm{Na}_{2} \mathrm{CO}_{3}+\mathrm{CH}_{4} \\
\mathrm{Ca}\left(\mathrm{C}_{2} \mathrm{H}_{3} \mathrm{O}_{2}\right)_{2} \rightarrow \mathrm{CaCO}_{3}+\mathrm{C}_{3} \mathrm{H}_{6} \mathrm{O} \text { (acetone) }
\end{gathered}
$$

The decomposition of sodium acetate is not limited to reaction (45), and numerous hypothetical decomposition reactions may be written in which the carbon oxidation state both increases and decreases to produce multiple products. Reactions (46) and (47) are two of many possible reactions that could occur. Many of these require water vapor, as in reaction (46). It is unknown if thermal decomposition produces ethane via reaction (47), but it is the principal product of electrolysis of sodium acetate (Williams and Hatch 1948, p.141). Only limited data on the actual thermal decomposition of sodium acetate was found. Sodium acetate reportedly melts without decomposition at $320^{\circ} \mathrm{C}$ (Coffey 1965) and decomposes (presumably in air) above $440^{\circ} \mathrm{C}$. The decomposition is complete at about $540^{\circ} \mathrm{C}$ and leaves $\mathrm{Na}_{2} \mathrm{CO}_{3}$ contaminated with elemental carbon (Duval 1963, p. 210; Duval 1955).

Reaction (48), the known elevated temperature reaction of sodium acetate with sodium hydroxide, is by far the dominant reaction and is used as a laboratory preparation of methane (Williams and Hatch 1948, p. 140). Reaction (46) can be considered a first step in this reaction with the neutralization reaction of $\mathrm{NaOH}$ and $\mathrm{NaHCO}_{3}$ driving reaction (46) to the right and regenerating the water used in reaction (46). Reactions similar to reaction (48) occur with alkali salts of other organic acids in which the carboxylate group is removed and converted to alkali carbonate, and a hydrogen atom is added to the organic entity remaining. Thus, sodium propionate would yield ethane as shown in reaction (54) below. 
Reaction (49) occurs with the alkaline earth acetates and similar reactions to produce ketones (or in the case of formates, aldehydes) occur with alkaline earth salts of various organic acids. This type of reaction occurs by removing the carboxylate group from one of the organic carboxylate anions and one oxygen atom from the other carboxylate anion of the salts and combining the remaining organic radicals (Williams and Hatch 1992, pp. 138-140).

Note that the appreciably higher decomposition temperature of sodium acetate $\left(\geq 440^{\circ} \mathrm{C}\right)$ compared to sodium formate ( $\geq 250^{\circ} \mathrm{C}$, discussed in the prior section), should increase its chance of direct reaction with $\mathrm{NaNO}_{3}$ and $\mathrm{NaNO}_{2}$, even if at higher temperatures sodium acetate does decompose to gaseous reductants as shown in reactions (46), (47), and (48). Sodium acetate is reported to react with $\mathrm{NaNO}_{3}$ and $\mathrm{NaNO}_{2}$ through reactions (50) and (51) below:

$$
\begin{gathered}
\mathrm{NaC}_{2} \mathrm{H}_{3} \mathrm{O}_{2}+4 \mathrm{NaNO}_{3} \rightarrow 4 \mathrm{NaNO}_{2}+1 / 2 \mathrm{Na}_{2} \mathrm{CO}_{3}+3 / 2 \mathrm{CO}_{2}+3 / 2 \mathrm{H}_{2} \mathrm{O} \\
\mathrm{NaC}_{2} \mathrm{H}_{3} \mathrm{O}_{2}+3 \mathrm{NaNO}_{2} \rightarrow 2 \mathrm{Na}_{2} \mathrm{CO}_{3}+3 / 2 \mathrm{H}_{2} \mathrm{O}+1 / 2 \mathrm{~N}_{2} \mathrm{O}+\mathrm{N}_{2}
\end{gathered}
$$

The reaction rates of sodium acetate with sodium nitrate and nitrite [reactions (50) and (51)] are slower than those with sodium formate [reactions (43) and (44)]. The sodium acetate reactions require 3 to $6 \mathrm{~h}$ for completion, while the sodium formate reactions require $\leq 1 \mathrm{~h}$ at $325^{\circ} \mathrm{C}$ (Kozlowski and Bartholomew 1968). Reactions (50) and (51), however, would probably be quite rapid at $440^{\circ} \mathrm{C}$ where simple decomposition just begins. On this basis, acetic acid might be a much more efficient reductant than formic acid. It may also be easier to estimate the amount of acetic acid required, since the relative extent of simultaneous decomposition and reduction reactions are no doubt affected by waste composition variables, catalysis, and rate of temperature increase. Recent experiments by $R$. S. Scheele, $\mathrm{PNL}$, in which an excess of an equimolar mixture of $\mathrm{NaNO}_{3}$ and $\mathrm{NaNO}_{2}$ was heated with sodium acetate indicated that $\mathrm{CH}_{4}$ is produced. Thus, even with acetate, some decomposition [via reaction (46)] occurred along with nitrate-nitrite oxidation.

Note that acetic acid is weaker than formic acid. Because of this, acetic acid may not dissolve as much of the hydrated oxides as formic acid does, therefore resulting in less improvement to feed rheology. Acetic acid is not expected to react or decompose significantly in the aqueous phase other than through the formation and decomposition of nitrous acid. The lack of aqueous phase reduction and decomposition reactions appears to be a considerable advantage.

The acidification of waste using a combination of nitric and organic acid would allow lower $\mathrm{pH}$ (and possibly better rheology properties) to be obtained. But if the organic acid were volatile like acetic acid, the organic acid would likely be lost. Nonvolatile organic acids and nonvolatile nonacidic organic compounds could be used in this manner. Example include the use of sucrose with nitric acid acidification.

Table 2.1 lists the properties of several organic compounds (mostly acids) that could be used to reduce oxidizing species in waste glass melting. The values of reducing equivalent given in Table 2.1 are based on a theoretical $100 \%$ efficiency and do not consider potential loss of reducing gases due to low temperature decomposition reactions competing with reduction. Table 2.1 is presented to illustrate the range of average $\mathrm{C}$ oxidation states and reducing capacities available in nonvolatile organic 
Table 2.1. Properties of Some Potential Reducing Agents for Waste Glass Melting

\begin{tabular}{|c|c|c|c|c|}
\hline Compound & $\begin{array}{c}\text { Average Carbon } \\
\text { Oxidation State }\end{array}$ & $\begin{array}{c}\text { Reducing } \\
\text { Equivalents/Mole }\end{array}$ & $\begin{array}{c}\text { Reducing } \\
\text { Equivalents/Gram } \\
\text { Compound } \\
\end{array}$ & $\begin{array}{l}\text { Acid Dissociation } \\
\text { Constants, }-\log K^{(a)}\end{array}$ \\
\hline Oxalic Acid & 3.00 & 2 & 0.0222 & $1.12,3.68$ \\
\hline Formic Acid & 2.00 & 2 & 0.0435 & 3.77 \\
\hline Glyoxylic Acid & 2.00 & 2 & 0.0541 & \\
\hline Tartaric Acid & 1.5 & 10 & 0.0667 & $3.04,4.16$ \\
\hline Malonic Acid & 1.33 & 8 & 0.0769 & $2.80,5.60$ \\
\hline Glycolic Acid & 1.00 & 6 & 0.0789 & 3.83 \\
\hline Pyruvic Acid & 0.67 & 10 & 0.114 & 2.49 \\
\hline Acetic Acid & 0.00 & 8 & 0.133 & 4.76 \\
\hline Sucrose & 0.00 & 44 & 0.129 & \\
\hline Graphite & 0.00 & 4 & 0.333 & \\
\hline Propionic Acid & -0.67 & 14 & 0.212 & 4.89 \\
\hline Polyethylene & -2.00 & & 0.429 & \\
\hline HEDTA $^{(b)}$ & 0.20 & $38^{(c)}$ & $0.139^{(c)}$ & $2.39,5.37,9.93$ \\
\hline
\end{tabular}

(a) Sillen and Martell (1964). Successive dissociation constants are given where appropriate.

(b) $\mathrm{N}^{\prime}\left(-2\right.$ hydroxyethyl) ethylenediamine-NNN ${ }^{\prime}$ triacetic acid, which is one of many organics present in some Hanford wastes.

(c) Based on the assumption that the nitrogen atoms present do not change oxidation state and in so doing also act as reductants.

materials (in the cases of the acids as their salts). Carbon oxidation states range from 3.00 for oxalic acid to -2.00 for polyethylene, while the reducing capacity per gram compound changes over 19-fold between these two compounds.

Oxalic acid has the oxidation state of an equimolar mixture of $\mathrm{CO}$ and $\mathrm{CO}_{2}$ and thus is expected to decompose with little carbon production via reaction (41). The decomposition is reported to follow reaction (41) to $>98.6 \%$, but it is also reported that some carbon from CO decomposition can sometimes be found in the remaining $\mathrm{Na}_{2} \mathrm{CO}_{3}$ (Duval 1963, p. 210). In addition, the decomposition rate reportedly becomes significant only above $500^{\circ} \mathrm{C}$ (Duval 1963, p. 210), and it seems likely that a reaction with nitrate and nitrite would be rapid below that temperature. Thus, oxalic acid is a logical choice as a reductant that leaves little carbon, but the amount of $\mathrm{Fe}$ (III) that would be reduced before decomposition is less certain. Oxalic acid is a stronger acid than formic acid, but because it forms many insoluble salts, its effect on rheology might not be beneficial. Oxalic acid is also of limited solubility, making its addition as a solution more difficult. Since it is nonvolatile, oxalic acid would not be lost from nitric acid acidified feeds.

The simple monocarboxylic acids become more reducing per carbon atom as the chain length increases. Thus, the average carbon oxidation state ranges from 2.00 for formic acid, through 0.00 for acetic acid, to -0.67 for propionic acid, and will approach -2.00 as the chain length approaches infinity. 
On the basis of limited data (Kozlowski and Bartholomew 1968), the reactions of sodium propionate with sodium nitrate and nitrite have been suggested to be as follows:

$$
\begin{gathered}
\mathrm{NaC}_{3} \mathrm{H}_{5} \mathrm{O}_{2}+7 \mathrm{NaNO}_{3} \rightarrow 7 \mathrm{NaNO}_{2}+1 / 2 \mathrm{Na}_{2} \mathrm{CO}_{3}+5 / 2 \mathrm{CO}_{2}+5 / 2 \mathrm{H}_{2} \mathrm{O} \\
\mathrm{NaC}_{3} \mathrm{H}_{5} \mathrm{O}_{2}+5 \mathrm{NaNO}_{2} \rightarrow 3 \mathrm{Na}_{2} \mathrm{CO}_{3}+1 / 2 \mathrm{~N}_{2} \mathrm{O}+2 \mathrm{~N}_{2}+5 / 2 \mathrm{H}_{2} \mathrm{O} \\
\mathrm{NaC}_{3} \mathrm{H}_{5} \mathrm{O}_{2}+\mathrm{NaOH} \rightarrow \mathrm{Na}_{2} \mathrm{CO}_{3}+\mathrm{C}_{2} \mathrm{H}_{6}
\end{gathered}
$$

If excess sodium propionate is used in waste glass melter feed, decomposition yielding some carbon is expected. The theoretical (assuming no loss of reducing gases) reducing capacity of propionic acid would be about five times that of formic acid on a weight basis. Its decomposition temperature is no doubt higher, so it is more likely to react with nitrate below its decomposition temperature. Propionic acid is, to a slightly greater extent than acetic acid, weaker than formic acid, which might result in less feed rheology improvement.

Tartaric acid (as crude potassium acid tartrate, argols) has been long used in controlled amounts as a reductant in fire assaying to reduce and precipitate the desired fraction of $\mathrm{Pb}$ from $\mathrm{PbO}$-containing. melts (glasses) to carry noble metals. Sucrose and starch have been used in simulated nuclear waste glass melting. If amounts are used above what is required to react with oxidants, principally nitrate and nitrite, both are expected to produce carbon during decomposition (pyrolysis). Volatile reducing gases can also be expected during pyrolysis. The pyrolytic carbon, if not excessive, can then be expected to react with Fe(III). An advantage of these higher molecular weight organics (as well as of oxalic acid and some other lower molecular weight organics) is that they do not form volatile free acids. Thus, nitric acid could be used to acidify the waste for dissolving hydrous oxides for theology purposes without converting the reductant to a volatile acid, which could be lost.

Carbon has the advantage over organic compounds of being nonvolatile, so it should remain in the cold cap and melt until reaching a temperature at which it reacts rapidly with oxidants. The reaction of carbon with $\mathrm{NaNO}_{3}$ or $\mathrm{NaNO}_{2}$ is important to the chemistry of black gun or blasting powder (normally a mixture of carbon, sulfur, and sodium or potassium nitrates), and studies of the reaction rates may be available in the literature. Burger et al. (1973) conducted limited studies. They reported a rapid exothermic reaction of $\mathrm{NaNO}_{3}$ and carbon at $450^{\circ} \mathrm{C}$, a sharp exothermic reaction at about $500^{\circ} \mathrm{C}$ in mixtures of carbon with previously calcined synthetic salt-cake waste, a smooth reaction of a mixture of $93 \% \mathrm{Na}_{2} \mathrm{CO}_{3}$ and $7 \% \mathrm{NaNO}_{3}$ with carbon at $\sim 500^{\circ} \mathrm{C}$, and an extremely rapid and vigorous exothermic reaction when powdered carbon was gradually added to a melt at $850^{\circ} \mathrm{C}$ that originally contained $\mathrm{NaNO}_{3}$ but in which only $15 \%$ to $20 \%$ of the original combined nitrogen remained.

On the basis of the Burger et al. (1973) results, it appears that using powdered carbon in the cold cap would destroy nitrate and nitrite at temperatures below those at which sufficient melt forms to close off cold-cap porosity $\left(\sim 700^{\circ} \mathrm{C}\right)$. The only way in which reducing capacity can be lost using carbon is through oxidation of the carbon only to $\mathrm{CO}$ with its loss from the cold cap. Burger et al. (1973, p. 45) found essentially no reaction of gaseous $\mathrm{CO}$ with molten sodium nitrate at $700^{\circ} \mathrm{C}$ and about $50 \%$ 
reduction of the nitrate in $1 \mathrm{~h}$ by $\mathrm{CO}$ bubbling through the melt at $775^{\circ} \mathrm{C}$. Thus, unless catalysis by cold-cap components occurs, any $\mathrm{CO}$ that formed would be lost.

A variety of other reducing agents have been used in glassmaking. These include cyanides, silicon, silicon carbide, and various metals (Weyl 1951). These reductants have largely been used to control glass color. The cyanides would undoubtedly react rapidly with nitrate and nitrite at a low temperature $\left(-400^{\circ} \mathrm{C}\right)$ but others, such a Si and $\mathrm{SiC}$, might not. Silicon and $\mathrm{SiC}$ have the advantage of nonvolatility and produce $\mathrm{SiO}_{2}$, which is added to the waste glass anyway.

\subsection{Waste Feed Types}

This section addresses the differing chemistry that occurs in the melter cold cap as a function of whether the melter feed is alkaline or acidic and whether it does or does not contain reductants.

\subsubsection{Alkaline Wastes}

In waste glassmaking, alkaline waste feeds will normally contain significant amounts of $\mathrm{NO}_{3}^{-}$, $\mathrm{NO}_{2}^{-}$, aluminate, $\mathrm{OH}^{-}$, and $\mathrm{CO}_{3}^{2-}$, and alkali metal ions. Assuming a $25 \mathrm{wt} \%$ loading of nonvolatile waste oxides in the final waste glass, it is estimated that glass feed made from washed NCAW sludge will have 1.1 moles $\mathrm{NO}_{3}^{-}+\mathrm{NO}_{2}^{-}$(as alkali metal salts), 0.25 moles $\mathrm{CO}_{3}^{2-}, 0.44$ moles $\mathrm{Al}$, and 0.1 moles $\mathrm{OH}^{-}$per $\mathrm{kg}$ of final glass. (a) The hydroxide value may be somewhat higher since it appears that washing with at least $0.1 \mathrm{M} \mathrm{NaOH}$ will be required to prevent conversion of aluminate to freshly precipitated $\mathrm{Al}(\mathrm{OH})_{3}$, which would cause difficulty in solids-liquid separation (discussion with G. J. Lumetta, PNL, 1993). A significant portion of the Al would probably be present as aluminate that, if not washed out, is almost equivalent in alkalinity to an equal amount of hydroxide. The alkaline feeds for the simulated NCAW glass (PSCM-11) for which foaming data were reported by Goldman, Brite, and Richey (1986), was clearly not made to this composition. In particular, the alkali nitrate level and to a lesser extent, the hydroxide level in PSCM-11 were significantly lower than currently anticipated for NCAW. (a)

Compared to waste of the same initial composition that has been acidified with nitric acid, alkaline waste can be expected to exhibit several major chemical differences that may markedly affect cold-cap chemistry. First, the presence of free strong bases (both $\mathrm{OH}^{-}$and aluminate) of alkali metals allows oxidation reactions that produce the highest possible oxidation states of multivalent metal ions to proceed under their most favorable conditions. Thus, free strong bases provide the optimum conditions for formation of manganates [reactions (4),(6), and (7)], chromates and dichromates [reactions (12), (14), and (15)], nickelates, and ferrates [reactions (23) and (25)]. Most of these highly oxidized species will persist at least until significant overall melting and silica dissolution occurs to lower the melt basicity, which destabilizes many of these species and results in $\mathrm{O}_{2}$ evolution. Some of the oxidized species such as $\mathrm{Cr}(\mathrm{VI}), \mathrm{Ce}$ (IV) (which is also stabilized by alkaline systems), and $\mathrm{Fe}$ (III) will persist to considerably higher temperatures (Schreiber et al. 1984). Alkaline, high-carbonate wastes

(a) Smith, R. A. 1991. Revision of Pretreated Neutralized Current Acid Waste Composition for FY 1991 Pilot Testing. Westinghouse Hanford Company letter to Mr. J. M. Creer, January 21, 1991, Correspondence No. 9150110. 
without significant free hydroxide will less effectively promote these oxidation reactions than hydroxide and aluminate wastes, but will nevertheless promote the reactions at higher temperatures where $\mathrm{Na}_{2} \mathrm{CO}_{3}$ becomes less stable, providing that the oxidized product is sufficiently stable at such temperatures [reaction (13)].

Second, the presence of significant amounts of sodium nitrite in alkaline waste (projected mole ratio $\left.\mathrm{NaNO}_{2} / \mathrm{NaNO}_{3}=3.75\right)^{(\mathrm{a})}$ allows formation of chromate [reaction (16)] at relatively low temperatures and presumably also manganates, ferrate, and possibly nickelates without consumption of free base or with reduced consumption of free base. These relatively low temperature reactions are not possible with acidic wastes because nitrous acid is not stable, and nitrites are thus decomposed in acidic solutions.

Third, the presence of $\mathrm{NaOH}$ (and $\mathrm{NaNO}_{2}$, which will also be present in alkaline waste) maximizes the temperature range and amount of liquid phases that can act as reaction fluxes in the cold cap. Thus, heating aqueous $\mathrm{NaOH}$ solutions at atmospheric pressure will not produce a solid phase up to $1150^{\circ} \mathrm{C}$, a molten $\mathrm{NaNO}_{3}-\mathrm{NaNO}_{2}$ eutectic will form at $226^{\circ} \mathrm{C}$, and other eutectics of $\mathrm{NaNO}_{3}$ or $\mathrm{NaNO}_{2}$ with $\mathrm{NaOH}$ having slightly higher melting points also form if adequate $\mathrm{NaOH}$ is present. Pure $\mathrm{NaNO}_{2}$ melts at $284^{\circ} \mathrm{C}$ and $\mathrm{NaNO}_{3}$ melts at $309^{\circ} \mathrm{C}$; these will persist as liquid phases at least until liquid borates and other liquids are forming. It can then be concluded that liquid phases providing fluxes for oxidation reactions and other reactions that occur in glassmaking exist at all temperatures in cold caps when highly alkaline ( $\mathrm{NaOH}$-containing) feeds are processed. These fluxes will increase the extent of completion of those reactions that are thermodynamically possible at lower temperatures, including the oxidation reactions of $\mathrm{NaNO}_{3}$ and $\mathrm{NaNO}_{2}$.

Fourth, wastes containing free $\mathrm{NaOH}$ should retain water to much higher temperatures than wastes of the same composition that are initially acidic. Most metal nitrates present in acidic wastes either do not hold water strongly (e.g., $\mathrm{NaNO}_{3}, \mathrm{KNO}_{3}$ ) or they decompose or lose water at relatively low temperatures $\left[\mathrm{Fe}\left(\mathrm{NO}_{3}\right)_{3} \cdot 6 \mathrm{H}_{2} \mathrm{O}, \mathrm{Al}\left(\mathrm{NO}_{3}\right)_{3} \cdot 9 \mathrm{H}_{2} \mathrm{O}\right.$ ]. In alkaline wastes, $\mathrm{NaOH}$ does not become anhydrous until about $400^{\circ} \mathrm{C}$ and does not lose its water of composition until it is converted by reaction to another compound (such as $\mathrm{Na}_{2} \mathrm{MnO}_{4}$ or sodium borate or silicate). This higher water content might be expected to increase reaction kinetics and to increase the liquid phase content of the cold cap as a function of temperature. It also might affect melt viscosity and surface tension.

Goldman, Brite, and Richey (1986) reported for each of three oxidized glass compositions a positive linear correlation of glass reboil pressure with the water content of the glass samples. For the same glass samples and measured reboil pressures, two of three glass compositions showed a positive linear correlation of the reboil pressure with the equivalents of oxidizing species stronger than Fe(III) present in the samples. Goldman, Brite, and Richey (1986) apparently did not recognize that the same data (reboil pressures) cannot be linearly proportional to two different independent variables and that, if the data are valid, the equivalents of oxidizing species in the glass must be linearly related to the glass water content for at least two of the three glasses. Why such a relationship between water content and oxidant content of the glass would occur is not certain, but it does point to a possible consequence of varying water content and, thus, to a possible difference between strongly alkaline and acidic feeds.

(a) Smith, R. A. 1991. Revision of Pretreated Neutralized Current Acid Waste Composition for FY 1991 Pilot Testing. Westinghouse Hanford Company letter to Mr. J. M. Creer, January 21, 1991, Correspondence No. 9150110. 
Addition of moist substances to hot glass is known to remove oxygen from glass (as would a sweep of any other gas through the molten glass) (Weyl 1951, p. 129). It seems likely then that the wateroxygen relationship in the Goldman, Brite, and Richey (1986) results may be due to this, and the samples that lost more water (due to probable slight differences in final melter temperatures) also lost more oxygen.

From the above discussion, it should be clear that alkaline feeds to the glass melter provide the most optimum conditions for producing and maintaining the maximum quantities of oxidants to the upper temperature limits of their stability. The highly alkaline (high $\mathrm{OH}^{-}$) feeds should result in formation of manganates, chromates, ferrates, nickelates, and possibly other high oxidation state species in the cold cap. Some of these will decompose at the temperatures where melt acidification by dissolving silica occurs and others such as $\mathrm{Cr}(\mathrm{VI})$ will persist to much higher temperatures. Based on the reactions discussed earlier in this report, the tendency for formation of these high oxidation state species should increase with increasing amount and strength of the waste alkalinity $\left(\mathrm{OH}^{-}\right.$versus $\mathrm{CO}_{3}^{2-}$ ). Since alkali nitrates and nitrites are primary oxidants that produce other high oxidation state species, production of these oxidized species is expected to increase as the waste alkali nitrate and nitrite concentrations increase, at least up to some limiting value. The degree of oxidation occurring in the cold cap may also depend on the alkali nitrite/nitrate ratio, particularly if alkali content is limited.

As discussed early in this report, historical melter experience has indicated that alkaline melter feeds have produced significantly more severe foaming than acidic feeds. It is expected that highly alkaline feeds containing both alkali nitrates and nitrites will produce the highest possible degree of highly oxidized metal species throughout the temperature range of the cold cap and on to the final glass. This, in turn, should provide the highest possible extent of oxygen evolution in the temperature range where "initial melting" and the bulk of the homogenization of the components occur, resulting in the decomposition of the least stable of the high oxidation state species (ferrates, nickelates, and manganates) formed in the cold cap.

In spite of the significant differences expected in cold-cap chemistry between alkaline and otherwise similar acidic feeds, initially acidic but otherwise similar high alkali nitrate feeds are expected to also produce very oxidized melts. For this reason, it is by no means clear that differences in amounts of oxidized species formed in the cold cap or particularly surviving into the molten glass adequately explain the differences in foaming behavior that have been observed between alkaline and acidic feeds.

\subsubsection{Acidic Wastes}

Acidic feeds for nuclear waste glassmaking will contain significant amounts of $\mathrm{NO}_{3}^{-}$and virtually no $\mathrm{NO}_{2}^{-}$because of the instability of nitrous acid. Commercial reprocessing wastes, which are stored acidic, might or might not have high alkali nitrate contents depending on the chemicals used in reprocessing. Hanford wastes (along with Savannah River and West Valley wastes), which have been initially neutralized with sodium hydroxide, will have high alkali nitrate content unless prepared from sludges that were exhaustively washed to remove alkali nitrates, nitrites, and carbonates before reacidification. It should be emphasized that nitric acid acidification of an originally alkaline waste will destroy essentially all nitrite and carbonate but will actually increase the total oxidizing capacity of the waste. This occurs because all destroyed alkali nitrites and carbonates are converted to nitrates, and nitrate has more oxidizing capacity than nitrite, and the carbonates were not oxidizing. Depending on 
the degree of acidification of alkaline wastes, various other metal ions present including alkaline earths, rare earths, $\mathrm{Fe}$, and $\mathrm{Al}$, will also be put into solution as nitrates.

As stated earlier, acidified feeds have neither free base nor nitrite to drive low temperature oxidation reactions in the cold cap to produce ferrates, manganates, chromates, or nickelates. At low temperatures, transition metal, and at somewhat higher temperatures aluminum and lanthanide nitrates, begin to decompose but do not provide strong base. Transition metal nitrate decomposition reactions such as (2), (11), (18), and (19) begin at temperatures as low as $40^{\circ} \mathrm{C}$, and many are complete by $300^{\circ} \mathrm{C}$. The metal oxide products are only weakly basic and the gases produced (when mixed with water vapor and air) are quite acidic; during these decompositions the system can be considered to remain acidic. Several of these nitrates melt in their water of hydration, so liquid phases will persist to above the boiling point of water and nitric acid but probably will not remain near the melting point of $\mathrm{NaNO}_{3}\left(309^{\circ} \mathrm{C}\right)$.

In the range from $300^{\circ}$ to $400^{\circ} \mathrm{C}$, reaction (14) can be expected to begin. The reaction of $\mathrm{NaNO}_{3}$ alone with other oxides, such as those of $\mathrm{Mn}$ and $\mathrm{Fe}$, cannot be expected to occur readily in the absence of either $\mathrm{Na}_{2} \mathrm{O}, \mathrm{NaOH}$, or $\mathrm{NaNO}_{2}$. Therefore, oxidation of these metals cannot be expected to become significant until decomposition of $\mathrm{NaNO}_{3}$ to produce first $\mathrm{NaNO}_{2}$ [reaction (26)] and then $\mathrm{Na}_{2} \mathrm{O}$ [reactions (27) and (28)]. Bond and Jacob's (1966) rate data indicate about $50 \%$ completion for reaction (26) in $1.5 \mathrm{~h}$ at $650^{\circ} \mathrm{C}$ and $50 \%$ completion for formation of $\mathrm{Na}_{2} \mathrm{O}$ in $4.7 \mathrm{~h}$ at $650^{\circ} \mathrm{C}$. Burger et al. (1973), however, found essentially no formation of $\mathrm{Na}_{2} \mathrm{O}$ at $775^{\circ} \mathrm{C}$ in $2 \mathrm{~h}$. In these complex waste feed mixtures, decomposition of $\mathrm{NaNO}_{3}$ and of the $\mathrm{NaNO}_{2}$ formed from it may be accelerated and may occur in the melter at much lower temperatures than in the pure salts, but this acceleration will be caused by the consumption of the formed $\mathrm{Na}_{2} \mathrm{O}$. Such acceleration could be caused by the metal oxidation reactions such as manganate and ferrate formation that require base, but acceleration is also likely to be caused by glass forming (and melting) reactions (borate and silicate formation) themselves. These latter reactions then consume free base that could otherwise drive transition metal oxidations.

Bickford, Diemer, and Iverson (1986) (as well as P. Smith of PNL) ${ }^{(a)}$ found that nuclear waste glass feeds melt adequately to consolidate and produce maximum foaming at about $700^{\circ} \mathrm{C}$ and slightly above. Borates and silicates are assumed to be entering the melt phase at this point. It would appear then that in the melter cold cap, free $\mathrm{Na}_{2} \mathrm{O}$ or significant amounts of $\mathrm{NaNO}_{2}$ may not form from $\mathrm{NaNO}_{3}$ to allow formation of manganates, ferrates, etc. under conditions where the latter are reasonably stable.

It should be emphasized that the more stable high oxidation state species, such as $\mathrm{Cr}$ (VI), $\mathrm{Ce}(\mathrm{IV})$, and probably $\mathrm{Mn}$ (III), will form even at the glass-forming temperature since the decomposing sodium nitrate will be strongly oxidizing. Thus, slightly above the glass formation temperature, little difference would be expected between the amount of oxidants present in glass melts from otherwise similar alkaline and acidic waste. Also, the total amount of $\mathrm{O}_{2}$ released by glass production from acidified waste originally containing nitrite should be higher than by glass production from the original alkaline waste.

(a) Smith, P. 1993. Unpublished work. 
As discussed earlier, experimental evidence suggests that acidic feeds do not produce foaming to the extent alkaline feeds do. It is very questionable how well the benefit, if any, of added reducing agents has been proven. Although there is an expected difference in redox chemistry between alkaline and acidic feeds with more high oxidation state metal species expected to form in an alkaline waste cold cap, these species are expected to decompose at the glass forming (acidic component dissolution) temperature stage, and there may be other effects that should not be ignored. Alkaline wastes contain alkali carbonates, hydroxide, and nitrites that are not present in the same wastes that have been acidified with nitric acid. If any of these react with the source of silica (normally frit) at a lower temperature than does sodium nitrate, they may close off the pore structure at a lower temperature where melt viscosity is higher and gas release may also be greater.

\subsubsection{Acidified Reduced Waste}

Initially alkaline wastes (Hanford, Savannah River, or West Valley) can be acidified in two ways to produce acidified reduced waste. They can be acidified with nitric acid and a reducing agent (not necessarily an acid) may be added, or they can be acidified with an organic acid that also serves as a reductant. The acidification dissolves some of the hydrous oxides present in the initially alkaline waste and presumably improves the feed rheology and pumpability. The acidification also eliminates hydroxide, carbonate, and nitrite from the feed slurry. This treatment eliminates reactions in the cold cap that require these species, except at temperatures above which they may re-form. Thus, in the reactions of carbonaceous reductant with sodium nitrate, sodium carbonate is formed; in the absence of any or sufficient reductant, thermal decomposition of sodium nitrate will form sodium nitrite; and at sufficient temperature sodium nitrite in turn decomposes to $\mathrm{Na}_{2} \mathrm{O}$ which with water vapor forms $\mathrm{NaOH}$.

The formation of $\mathrm{Na}_{2} \mathrm{CO}_{3}$ by the reaction of carboneous reductants with sodium nitrate occurs at relatively low temperature (about $300^{\circ}$ to $350^{\circ} \mathrm{C}$ with formate). If insufficient reductant is present, this limited reductant may reduce some of the sodium nitrate only to sodium nitrite in the $300^{\circ}$ to $500^{\circ} \mathrm{C}$ temperature range depending on which reductant is used. On the other hand, thermal decomposition of sodium nitrate to nitrite requires $>500^{\circ} \mathrm{C}$, and $\mathrm{NaOH}$ production by decomposition of $\mathrm{NaNO}_{2}$ in the presence of $\mathrm{H}_{2} \mathrm{O}$ vapor does not appear to occur in the pure salt until above $700^{\circ} \mathrm{C}$. If adequate reductant is present and is not lost due to low temperature decomposition into reducing gases that escape from the reaction zone, the reductant reaction should certainly prevent $\mathrm{Na}_{2} \mathrm{O}$ or $\mathrm{NaOH}$ from forming at all, should prevent the existence of $\mathrm{NaNO}_{2}$ above $\sim 500^{\circ} \mathrm{C}$, and $\mathrm{Na}_{2} \mathrm{CO}_{3}$ should be the strongest base that can form. This $\mathrm{Na}_{2} \mathrm{CO}_{3}$ will then be the principal glass-forming alkali metal compound in the waste, as opposed to a mixture of $\mathrm{NaOH}, \mathrm{Na}_{2} \mathrm{CO}_{3}, \mathrm{NaNO}_{3}$, and $\mathrm{NaNO}_{2}$, in the case of untreated (alkaline) waste, or $\mathrm{NaNO}_{3}$ (and $\mathrm{NaNO}_{2}$ from $\mathrm{NaNO}_{3}$ decomposition) in acidified but unreduced waste. In both untreated alkaline and acidified unreduced wastes, $\mathrm{Na}_{2} \mathrm{O}$ and $\mathrm{Na}_{2} \mathrm{O}_{2}$ may form in decomposition of $\mathrm{NaNO}_{3}$ and $\mathrm{NaNO}_{2}$ at high temperatures. The difference in these feed types undoubtedly affects the temperature at which sufficient melt formation occurs to close off frit porosity.

Note that if a waste is acidified (with either $\mathrm{HNO}_{3}$ or organic acid) and carbonaceous reductant is used in insufficient quantity to completely reduce nitrate in the cold cap, the waste components will react to leave a carbonate, nitrate, and nitrite mixture. Although this combination is not as alkaline as untreated alkaline waste, it may well provide an environment more conducive to oxidation of metals such as $\mathrm{Mn}, \mathrm{Fe}, \mathrm{Ni}$, and $\mathrm{Cr}$ to their highest oxidation states than waste treated with only nitric acid. The latter, containing only $\mathrm{NaNO}_{3}$, will not provide base to drive the oxidation reaction [such as reac- 
tions (4), (6), (7), (13), (15), (23), (25)] until $\mathrm{NaNO}_{2}$ decomposition occurs and where most of the high oxidation metal species are destabilized anyway because of silica dissolution.

The acidification of the waste with nitric acid actually increases the oxidizing capacity of the glass feed by converting carbonates, hydroxides, and nitrites to nitrates. Acidification with an organic acid converts hydroxides, carbonates, and nitrites to metal salts of the organic acids, thus lowering both alkalinity and oxidizing capacity. Many organic acids will not react with nitrate in the aqueous solutions, leaving it unaffected. Some, including formic acid, partially react under catalysis by waste components with nitrate, further lowering the oxidizing capacity of the feeds. Unfortunately, these reactions with nitrate in aqueous solution do not necessarily follow the same stoichiometry of the higher temperature reactions, making it more difficult to quantitatively predict the effect of the reductant on the final glass redox state.

The use of organic acids creates some difficulties. In a well washed waste sludge having a low nitrate content, addition of sufficient organic acid to neutralize and dissolve hydroxides, carbonates, and hydrous oxides and to destroy nitrites (acidify the waste) will conceivably leave sufficient metal organic salts to overreduce the glass. On the other hand, organic acid acidification of high nitrate waste that is low in alkalinity may not provide enough organic acid to react in the melter with the nitrate, resulting in a highly oxidizing glass. If more of a volatile organic acid (formic, acetic, etc.) were used, the acid would boil away before reaching a temperature in the cold cap at which it would react with nitrate. The use of a nonvolatile acid that adequately improved rheology would solve this problem, but high alkalinity and low nitrate levels would still result in overreduction. Basically, this problem results from the fact that it is impossible to optimize the use of one reagent for two independent purposes. In this case, the purposes are to control redox level which in turn is thought by many to control melter foaming and to improve feed rheology.

Formulas based only on the amounts thought to be required to neutralize or dissolve hydroxides, carbonates, and hydrous oxides; to react with nitrite; and to reduce $\mathrm{HgO}$ to elemental $\mathrm{Hg}$ and $\mathrm{MnO}_{2}$ to $\mathrm{Mn}^{2+}$ have been proposed for determining the amount of formic acid to be used in melter feed pretreatment. ${ }^{(a, b, c)}$ These formulas must be considered useful only for feed rheology control; they do not define the redox condition of the final glass. The use of nitric acid acidification along with a nonvolatile reductant should in theory solve this problem. Nitric acid would be used to neutralize and dissolve hydroxides, carbonates, and hydrous oxides, and the reductant would be added on the basis of the amount of nitrates present after acidification. Note that this approach does not completely solve the problem of being able to simply calculate the amount of reductant needed from chemical stoichiometry. This is partly because (as discussed in Sections 2.2.1 and 2.2.2) organic reductants probably, to different degrees, decompose to emit reducing gases at or below the temperatures at which they completely reduce oxidants (nitrate particularly in acidic wastes), thus losing reducing gases and

(a) Hsu, C. W. 1990. Formic Acid Requirement in the DWPF Chemical Processing Cell. Westinghouse Savannah River Company, Letter Report to J. R. Knight, WSRC-RF-90-0554.

(b) Larsen; D. E., ed. 1988. Hanford Waste Vitrification Plant Process Chemistry and Technology. HWVP-86-V1143B, Pacific Northwest Laboratory, Richland, Washington.

(c) Farnsworth, R. K. 1987. The Effect of Feed Composition and Formic Acid Addition on Glass Redox State. HWVP-V110203A, PRMC-2202044, Pacific Northwest Laboratory, Richland, Washington. 
reduction efficiency. An example of this would be the decomposition of alkaline earth carboxylate salts formed in wastes acidified by organic acids to volatile ketones via reaction (49). It is also partly due to the fact that not all nitrate salts behave the same chemically.

In acidic wastes (depending on the extent of acidification) not only are alkali nitrates (principally sodium nitrate) present, but alkaline earth, $\mathrm{Al}$, and various transition metal nitrates are present as well. Some of these, such as ferric nitrate (reaction 19), decompose at rather low temperatures. In general, the less basic the metal oxide produced, the lower the nitrate decomposition temperature. At first glance, it might be assumed that nitrates that decompose at low temperature might not survive to temperatures where they would react with reducing agents that would not react with $\mathrm{NaNO}_{3}$ until about $300^{\circ}$ to $500^{\circ} \mathrm{C}$. This is probably not the case, however. Most nitrates appear to become kinetically active oxidants at or near the temperature region where decomposition begins; this no doubt results from the production of very active intermediates during decomposition. Thus, higher valent transition metal nitrates may react violently with reductants at temperatures below $200^{\circ} \mathrm{C}$.

The more likely event is that the nitrogen-containing product $\left(\mathrm{NO}_{x}, \mathrm{~N}_{2} \mathrm{O}, \mathrm{N}_{2}\right)$ of the reduction may change depending on the temperature at which reaction occurs. This changes the redox stoichiometry. Reduction of metal nitrates that are reduced at low temperature might yield higher amounts of $\mathrm{NO}_{\mathrm{x}}\left(\mathrm{NO}\right.$ and $\mathrm{NO}_{2}$ ), and reactions that occur only at much higher temperatures would be more likely to convert a greater fraction of the combined nitrogen to $\mathrm{N}_{2} \mathrm{O}$ or particularly $\mathrm{N}_{2}$. This is because it is assumed that greater activation energy is required to form a N-N bond. On this basis, the amount of reductant required to produce a given final glass redox condition (such as $\mathrm{Fe}^{2+} / \mathrm{Fe}^{3+}$ ratio) likely cannot be exactly measured by the total acidified feed nitrate level.

\subsubsection{Alkaline Reduced Wastes}

Alkaline reduced wastes could be produced either by adding a neutral or alkaline organic reductant, including salts of organic acids, to alkaline waste without acidifying the waste, or by adding an organic acid reductant in insufficient quantity to acidify the waste. This free alkali will markedly change the nature of chemical reactions occurring in the cold cap. Not only does alkalinity favor oxidation of metal ions to their highest possible oxidation states (as discussed throughout Sections 2.1 and 2.3.1), but alkalinity will also affect the course of reaction of organic materials present in or added to the waste feed.

With organic acids as reductants, particularly including formic acid, the presence of alkalinity will lower the decomposition temperatures of the organic acid salts produced when the acids are added to the alkaline waste. These decompositions produce reducing gases that may remove most or all of the reducing capacity of the reductant from the cold cap without reduction occurring, depending on the extent to which these gases react before loss. This extent of loss of reductant depends on melter design and operating conditions; loss of reductant may be much different in laboratory-scale experiments than in a full-scale melter.

In the case of formic acid or formate salts, reaction (39), decomposition in an alkaline environment begins at $210^{\circ} \mathrm{C}$ and proceeds "smoothly" at $250^{\circ} \mathrm{C}$. On the other hand, the reaction of sodium formate with sodium nitrate and nitrite proceeds at comparable rates only at about $350^{\circ} \mathrm{C}$ (reactions 43 and 44). The result is that a large fraction of the formate will be decomposed to yield $\mathrm{H}_{2}$, which may escape before reacting with the oxidants, thereby significantly lowering oxidation state control 
efficiency. If all the sodium formate reacted with sodium hydroxide before it could react with sodium nitrate and nitrite, and $\mathrm{H}_{2}$ was lost by rapid diffusion from the glass feed mix, the reduction efficiency of the formate would be zero.

The same problem applies to the use of other organic acids such as acetic or propionic acids or their salts. Alkali hydroxides react with alkali acetates and propionates to form methane and ethane, respectively, [reactions (48) and (54)]. Any alkaline earth acetates and propionates that are present decompose to make volatile acetone and 3-pentanone, respectively, [reaction (49)], although alkaline earths are less likely to be present as organic carboxylate salts in alkaline wastes than in wastes acidified by organic acids. To the extent that these reactions occur at lower temperatures before the reduction of nitrates and nitrites, and the volatile products escape, the reduction efficiency is lowered. No information was obtained on the temperatures or rates of these reactions, but a significant loss of reductant efficiency must be assumed when using organic acids in alkaline wastes.

The effect of alkalinity on the decomposition or pyrolysis of organic reductants other than organic acids (such as sucrose, starch, etc.) is not as certain. It does appear that the extent of reduction versus decomposition reactions will be different in alkaline versus acidic wastes for many organic reductants, even if they are not organic acids.

The effect of alkalinity on the temperature and reaction rate of alkali nitrates and nitrites with organic reductants was not found in the literature. Though far from proven, it can be postulated that if ortho- and pyronitrates form from nitrate and alkali $\left(\mathrm{Na}_{2} \mathrm{O}\right.$ ) (Shams El Din and Hosary 1967a, 1967b; Kohlmuller 1959), they would stabilize N(V) in the melt and lower its reactivity toward reducing agents. This in turn would increase the extent of organic reductant loss due to decomposition relative to the extent of reduction. 


\subsection{Conclusions}

The use of reductants in general and of formic acid in particular to control foaming in nuclear waste glass preparation in liquid-fed ceramic melters is at best a poorly proven concept. The concept that reductants can be used to lower the oxygen fugacity in the glass-forming and higher temperature glass melt regions and that this in turn may prevent foaming problems in melters is a reasonable hypotheis. It is, however, poorly proven because experimental work in this field did not resolve this question. Indeed, it is unclear in what temperature regime in the melter the reactions occur that cause problem foaming. In this regard, remember that some gas release in the melter is to be expected at all temperature ranges (as temperature is increased) at least for unreduced glass mixtures.

There is strong reason to believe that other variables in the waste glassmaking process may be as or more important to melter foaming problems as the glass redox level. Data for past melter runs have indicated that acidic feeds (with nitric acid) without reductants did not foam significantly even when they had very high oxidizing capacities (high nitrate and especially high alkali metal nitrate levels). On the other hand, nonreduced alkaline feeds with much lower (several hundred-fold) nitrate levels exhibited serious foaming.

The redox chemistry of multivalent metals is expected to be significantly different during heating to glass temperature (cold-cap chemistry) for alkaline versus acidic feeds. Alkalinity in the presence of nitrate and nitrite should promote the formation of the highest possible oxidation states of the multivalent metals such as $\mathrm{Fe}, \mathrm{Cr}, \mathrm{Ni}, \mathrm{Mn}$, and $\mathrm{Ce}$. Many of these high oxidation state species will decompose releasing $\mathrm{O}_{2}$ at the temperature at which silica dissolves into the melt, thereby decreasing alkalinity. At this same temperature, the melt phase has high viscosity and should best retain gas.

This difference in redox chemistry and the possible difference in amount of gas produced between alkaline and acidic wastes is not a proven explanation of the apparent foaming differences between these types of wastes. The absence of nitrite, carbonate, and hydroxide in acidic wastes may change the temperature and rate of liquid melt phase formation versus acidic waste, and thus change the temperature at which foaming can occur.

The use of adequate amounts of reductant in the melter feeds should theoretically eliminate the capacity of the mixture to produce oxygen if the reductant reacts with the oxidants below the temperatures at which oxidant decomposition yields oxygen. This does not seem particularly difficult since most organics and carbon should react rapidly with nitrate and nitrite (the principal oxidants) well below $600^{\circ} \mathrm{C}$, and it is only near $600^{\circ} \mathrm{C}$ and above that significant decomposition of alkali nitrates and nitrites and higher oxidation state metals is expected to produce oxygen. However, the elimination of oxygen evolution, if brought about by using carbon or organic carbon-containing reductants, will not eliminate gas release in the glass-forming region from about $600^{\circ}$ to $800^{\circ} \mathrm{C}$. The reactions of nitrates and nitrite of the lower valent metals (principally alkali and alkaline earth metals) with carboncontaining reductants produce carbonates. These in turn release $\mathrm{CO}_{2}$ in this temperature region. This release may not peak at exactly the same temperature as the oxygen release would peak if reductants had not been used. 
What constitutes "adequate amounts of reductant" is difficult to predict. There is a significant amount of evidence that all organic compounds, even in acidic feeds and with nitrate and nitrite present, will partially decompose to produce reducing volatile gases simultaneously with their oxidation by nitrate and nitrite. These reduced gases $\left(\mathrm{H}_{2}, \mathrm{CO}, \mathrm{CH}_{4}, \mathrm{C}_{2} \mathrm{H}_{6}\right.$, acetone, etc.) may escape the cold cap carrying out little if any reduction. Both the amount of the gases and the extent to which they themselves carry out reduction will depend on various process variables such as feed rate, heating rate, and gas sweep rate. The efficiency of the reductant will change with these variables. Because of the difference in size and design of equipment, gas sweep rates, and nature of heating (uniform temperature versus varying temperature across a cold cap), it is particularly difficult to simulate melter conditions in the laboratory.

The amount of reductant required is therefore very difficult to estimate. This is particularly the case with formic acid, which decomposes and reacts with nitrite and to some extent nitrate by multiple routes in the aqueous phase and then in the cold cap as sodium formate decomposes by multiple routes. This decomposition of sodium formate occurs at or below the temperature at which it reacts with nitrate and nitrite salts. Heavier organic acids may offer some benefit in terms of reproducible reaction stoichiometries, but with acetate, even if heated with an excess of sodium nitrate and nitrite, some methane is produced. With organic acid salts in alkaline feeds, there is reason to believe that reduction efficiency may be lowered even further. This is because with alkali, decomposition to produce gases carrying all the reducing capacity of the salt is possible at relatively low temperatures compared to nitrate reduction.

Careful experimental studies are needed to determine if foaming in the melters can be controlled without reducing agents by methods such as $\mathrm{pH}$ control. If carefully designed studies show that reductants are needed, alternatives to formic acid should be examined in the hope of finding more predictable substitutes. Of particular interest would be carbon and nonvolatile organics that could be used in combination with nitric acid to control feed rheology. 


\subsection{References}

Bade, H., W. Bronger, and W. Klemm. 1965. "Der Verhalten von Nickeloxid zu Alkalimetalloxiden biem Erhitzen im Sauerstoffstrom." Bull. Soc. Chim (France) 1124.

Bailar, J. C., Jr., et al. 1973a. Comprehensive Inorganic Chemistry, Vol. 1. Pergamon Press, New York.

Bailar, J. C., Jr., et al., eds. 1973b. Comprehensive Inorganic Chemistry, Vol. 2. Pergamon Press, New York.

Bailar, J. C. et al. 1973c. Comprehensive Inorganic Chemistry, Vol. 3. Pergamon Press, New York.

Barney, G. S. 1976. Vapor-Liquid-Solid Phase Equilibria of Radioactive Sodium Salt Wastes at Hanford. ARH-ST-133, Atlantic Richfield Hanford Company, Richland, Washington.

Bickford, D. F., and R. B. Diemer, Jr. 1986. "Redox Control of Electric Melters with Complex Feed Compositions. Part I. Analytical Methods and Models." J. Non-Cryst. Solids 84:276.

Bickford, D. F., R. B. Diemer, Jr., and D. C. Iverson. 1986. "Redox Control of Electric Melters with Complex Feed Compositions. Part II. Preliminary Limits for Radioactive Waste Melters." J. of Non-Cryst. Solids, 84:285.

Bickford, D. F., P. R. Hrma, and B. W. Bowen II. 1990. "Control of Radioactive Waste Glass Melters: II. Residence Time and Melt Rate Limitations." J. Am. Ceram. Soc. 73:2903.

Bickford, D. F., A. Applewhite-Ramsey, C. M. Jantzen, and K. G. Brown. 1990. "Control of Radioactive Waste Glass Melters: I. Preliminary General Limits at Savannah River." J. Am. Ceram. 73:2896.

Bickford, D. F., C. J. Coleman, C-L. W. Hsu, and R. E. Eibling. 1992. "Noble Metal Catalyzed Formic Acid Decomposition, and Formic Acid Denitration." Ceramic Transactions, Nuclear Waste Management IV 23:283.

Blair, H. T., and J. M. Lukacs. 1980. Investigation of Foaming During Nuclear Defense-Waste Solidification by Electric Melting. PNL-3552, Pacific Northwest Laboratory, Richland, Washington.

Bond, B. D., and P.W.M. Jacobs. 1966. "The Thermal Decomposition of Sodium Nitrate." J. Chem. Soc. (A), p. 1265.

Brock, N. A. 1990. The Determination of the $\mathrm{Fe}^{2+} / \mathrm{Fe}^{3+}$ Ratio in Simulated Nuclear Glass by Ion Chromatography. Masters degree thesis presented to the Graduate School of Clemson University. Clemson, South Carolina.

Burger, L. L., J. L. Ryan, J. L. Swanson, and L. A. Bray. 1973. "Salt Cake Volume Reduction by Sodium Removal." BNWL-B-293, Pacific Northwest Laboratory, Richland, Washington. 
Cecille, L., and S. Halaszovich. 1986. Denitration of Radioactive Liquid Waste. Graham and Trotman Ltd., London.

Coffey, S., ed. 1965. Radd's Chemistry of Carbon Compounds, 2nd ed., Vol. 1, Part C, p. 132. Elsevier, New York.

Cotton, F. A., and G. W. Wilkinson. 1972. Advanced Inorganic Chemistry, 3rd ed. Interscience Publishers, New York.

Curlin, L. C., T. V. Bommaraju, and C. B. Hansson. 1991. "Alkali and Chlorine Products." KirkOthmer Encyclopedia of Chemical Technology, 4th ed., Vol. 1, pp. 938-1024. Wiley and Sons, New York.

Duval, C. 1955. "Sur la Stabilite Thermique des Etalons Analytiques. I." Anal. Chim. Acta. 13:32.

Duval, C. 1959a. "Sur la Stabilite Thermique des Etalons Analytiques. VI." Anal. Chim. Acta. 20:20.

Duval, C. 1959b. "Sur la Stabilite Thermique des Etalons Analytiques. VII." Anal. Chim. Acta 20:263.

Duval, C. 1963. Inorganic Thermogravimetric Analysis, 2nd ed. Elsevier, New York.

Freeman, E. S. 1956. "The Kinetics of the Thermal Decomposition of Sodium Nitrate and the Reaction Between Sodium Nitrite and Oxygen." J. Phys. Chem. 60:1487.

Gadalla, A.M.M., and H. W. Hennicke. 1973. "Reactivity of Ferric Oxide." Powder Met. Inst. 5:196. From Chemical Abstracts, Vol. 80, Abstract No. 41298.

Gibson, H. W. 1969. "The Chemistry of Formic Acid and Its Simple Drivatives." Chem. Rev. 69:673.

Glemser, O., and J. Einerhand. 1950. "Uber Hohere Nickelhydroxide." Z. anorg. u. allgem. Chem. 261:26.

Goldman, D. S. 1985. Investigation of Potential Analytical Methods for Redox Control of the Vitrification Process. PNL-5581, Pacific Northwest Laboratory, Richland, Washington.

Goldman, D. S. 1986. "Melt Foaming, Foam Stability and Redox in Nuclear Waste-Glass Vitrification." J. Non-Cryst. Solids 84:276.

Goldman, D. S., and D. W. Brite. 1986. "Redox Characterization of Simulated Nuclear Waste Glass." J. Am. Ceram. Soc. 69:411.

Goldman, D. S., D. W. Brite, and W. C. Richey. 1986. "Investigation of Foaming in Liquid-Fed Melting of Simulated Nuclear Waste Glass." J. Amer. Ceram. Soc. 69:413. 
Gordon, S., and C. Campbell. 1955. "Differential Thermal Analysis of Inorganic Compounds, Nitrates and Perchlorates of the Alkali and Alkaline Earth Groups and Their Subgroups." Anal. Chem. 27:1102.

Hartford, W. H, and R. L. Copson. 1964. "Chromium Compounds." Kirk-Othmer Encyclopedia of Chemical Technology, 2nd ed., Vol. 5, pp. 473-516. Wiley and Sons, New York.

Hay, J. O. 1952. "Manganese Compounds." Kirk-Othmer Encyclopedia of Chemical Technology, 1st ed, Vol. 8, pp. 736-764. Interscience Publishers, New York.

Hoshino, Y., T. Utsunomiya, and O. Abe. 1981. "The Thermal Decomposition of Sodium Nitrate and the Effects of Several Oxides on the Decomposition." Bull. Chem. Soc. Jpn. 54:1385.

Keller, C. 1972. "Lanthanide and Actinide Mixed Oxide Systems with Alkaline Earth Metals." MTP Int. Rev. Sci. Series One, Vol. 7, pp. 60-61 and 76-77.

Kerridge, D. H., and A. Y. Khudhari. 1975. "Molten Lithium Nitrate-Potassium Nitrate Eutectic: The Reactions of Compounds of Iron." J. Inorg. Nucl. Chem. 37:1893.

Kohlmuller, R. 1959. "Recherches sur les Orthonitrates et sur les Orthonitrites de Sodium et de Potassium." Ann. Chim. 4:1183.

Kozlowski, T. R., and R. F. Bartholomew. 1968. "Reactions Between Sodium Carboxylic Acid Salts and Molten Sodium Nitrate and Sodium Nitrite." Inorg Chem. 7:2247.

Kramer, C. M., Z. A. Munir, and J. V. Volponi. 1982. "Differential Scanning Calorimetry of Sodium and Potassium Nitrates and Nitrites." Thermochim. Acta 55:11.

Kramer, C. M., Z. A. Munir, and J. V. Volponi. 1983. "Simultaneous Dynamic Thermogravimetry and Mass Spectrometry of the Evaporation of Alkali Metal Nitrates and Nitrites." J. Therm. Anal. 27:401.

Lucktong, C., and P. Hrma. 1988. "Oxygen Evolution During MnO-Mn $\mathrm{M}_{4}$ Dissolution in a Borosilicate Melt." J. Amer. Ceram. Soc. 71:323.

Lumme, P., and K. Junkkarinen. 1968. "Thermogravimetric Studies. XI. Thermal Stability and Decomposition Kinetics of Ferrous Chloride Tetrahydrate, Sulfate Heptahydrate, Ferric Chloride Hexahydrate, Nitrate Nonahydrate, and Sulfate Hexahydrate in Air and Ferrous Chloride Tetrahydrate, and Ferric Chloride Hexahydrate in Dynamic Nitrogen." Suome Kemistlehti, B, 41:220. From Chemical Abstracts, Vol. 69, Abstract No. 54624.

Meisel, T., and Z. Halmos. 1971. "Thermal Behavior of Some Organic Compounds with Ionic Character." Therm. Anal. Proc. Int. Conf., (3rd) 3:43.

Meisel, T., Z. Halmos, K. Seybold, and E. Pungor. 1975. "Thermal Decomposition of Alkali Metal Formates." J. Therm. Anal. 7:73. 
Mellor, J. W. 1934. A Comprehensive Treatise on Inorganic and Theoretical Chemistry, Vol. XIII. Longmans, Green, and Company, New York.

Molinari, E., and J. L. Margrave. 1964. "Explosive Formation of Manganates Under Very High Pressures." Inorg. Chem. 3:898.

Muzyka, I. D., O. I. Shor, V. A. Kosenko, and A. S. Kutovoi. 1968. "Thermal Analysis of Some Salts Used for the Synthesis of Ferrites." Mater. Mezhotrasl. Soveshch. Metod. Poluch. Anal. Ferritoykh Mater. Syr'ya Nikh, 2nd 1966, 1:226. From Chemical Abstracts, Vol. 74, Abstract No. 93938.

Oswald, M. 1914. Ann. Chim (Paris) 1:100.

Paul, A. 1982. Chemistry of Glasses. Chapman Hall, New York.

Pernert, J. C. 1952. "Oxalic Acid." Kirk-Othmer Encyclopedia of Chemical Technology, 1st ed., Vol. 9, pp. 661-674. Interscience Publishers, New York.

Peters, V. M., K. H. Radeke, and L. Till. 1966. "Uber das thermische Verhalten von Kalium manganate (V)-(VI), und -(VII)." Z. Anorg. Allgem. Chem. 346:1.

Piepel, G. F., P. R. Hrma, S. O. Bates, M. J. Schweiger, and D. E. Smith. 1993. First-Order Study of Property/Composition Relationships for Hanford Waste Vitrification Plant Glasses. PNL-8502, Pacific Northwest Laboratory, Richland, Washington.

Purtov, A. I., I. I. Kalinichenko, and N. E. Ulanovskaya. 1970. "Thermal Decomposition of Ferric Nitrate Nonahydrate." Tr. Ural Politekh, Inst., No. 190, 64. From Chemical Abstracts, Vol. 76, Abstract No. 41465t.

Quin, J. P. 1911. Mellor's Comprehensive Treatise on Inorganic and Theoretical Chemistry, Vol. II, Suppl. II. Wiley and Sons, New York.

Ray, P. 1905. "The Nitrites of the Alkali Metals and Metals of the Alkaline Earths and Their Decomposition by Heat." J. Chem. Soc. 177.

Ray, J. D., and R. A. Ogg, Jr. 1956. "A New Method of Preparing Nitric Oxide." J. Am. Chem. Soc. $78: 5993$.

Reidies, A. H. 1981. "Manganese Compounds." Kirk-Othmer Encyclopedia of Chemical Technology, 3rd ed., Vol. 14, pp. 844-895. Wiley and Sons, New York.

Ritter, J. A., J. R. Zamecnik, and C. W. Hsu. 1992. "Hydrogen Generation During Treatment of Simulated High-Level Radioactive Waste with Formic Acid (U)." WSRC-MS-92-017. Manuscript prepared for presentation at International High-Level Radioactive Waste Management Conference, Las Vegas, Nevada, April 12-16, 1992. 
Rode, T. V., and G. A. Golder. 1956a. "Compounds of Constant and of Variable Composition in the Sodium Superoxide - Sodium Oxide System." Doklady Akad, Nauk, S.S.S.R. 110, 1001. See also Chemical Abstracts 50, 12621 e, 1956.

Rode, T. V., and G. A. Golder. 1956b. "Physiochemical Investigation of the System Sodium Superoxide-Sodium Oxide." Izvest. Akad. Nauk. S.S.S.R., Otdel, Khim, Nauk 290. See also Chemical Abstracts 51, 14460 c, 1957.

Schrieber, H. D., G. B. Balazs, B. E. Carpenter, J. E. Kirkley, L. M. Minnix, and P. L. Jamison. 1984. "An Electromotive Force Series in a Borosilicate Glass-Forming Melt." J. Amer. Ceram. Soc. 67:C-106.

Shams El Din, A. M., and A. A. El Hosary. 1967a. "On the Formation of Pyronitrate in Molten Salts." Electrochemica Acta 12:1665.

Shams El Din, A. M., and A. A. El Hosary. 1967b. "Pyronitrate: A New Anion of Pentavalent Nitrogen." J. Inorg, Nucl. Chem. 28:3043.

Shishido, S., and Y. Masuda. 1971. "Thermal Analysis of Various Metallic Formates." Nippen Kagaku Zasshi 92:309.

Shishido, S., and Y. Masuda. 1973. "Thermal Decomposition of Formates. II. Gaseous Products Formed in the Thermal Decomposition of Formats." Nippon Kagaku Kaishi 185.

Shishido, S., and Y. Masuda. 1976. "Thermal Decomposition of Formates. III. Thermal Decomposition of Alkali Metal Formates." Nippon Kagaku Kaishi 66.

Sillen, L. G., and A. E. Martell. 1964. Stability Constants of Metal-Ion Complexes. The Chemical Society, London.

Sirotkin, C. D. 1959. "Equilibrium in Melts of the Nitrates of Sodium and Potassium." Russian Journal of Inorganic Chemistry (English Translation) 4:1180.

Standiford, F. C., and W. L. Badger. 1954. "Properties of Strong Caustic Soda Solutions." Ind. Eng. Chem. 46:2400.

Sugiyama, K., and T. Takahashi. 1967a. "Formation of Nitrogen Oxide by the Reaction of Molten Sodium Nitrate or Sodium Nitrite with Chromic Oxide." Kogyo Kagaku Zasshi 70:830.

Sugiyama, K., and T. Takahashi. 1967b. "Formation of Nitrogen Oxides by Thermal Decomposition of Sodium Nitrate and Sodium Nitrite in the Presence of Various Oxides." Kogyo Kagaku Zasshi $70: 1465$.

Sulcek, Z., and P. Povondra. 1989. Methods of Decomposition in Inorganic Analysis. Chemical Rubber Company Press, Boca Raton, Florida. 
Thorpe, J. C., and M. A. Whiteley. 1947. Thorpes Dictionary of Applied Chemistry, Vol. V. Longmans, Green, and Company, New York.

Volf, M. B. 1984. "Chemical Approach to Glass." In Glass Science and Technology, Vol. 7. Elsevier, New York.

Voskrensenskaya, N. K., ed. 1961. Handbook of Solid-Liquid Equilibria in Systems of Anhydrous Inorganic Salts, Vol. I. Israel Program for Scientific Translations, Jerusalem, 1970.

Weyl, W. A. 1951. Coloured Glasses. The Society of Glass Technology, Sheffield, England.

Williams, R. J., and L. F. Hatch. 1948. An Introduction to Organic Chemistry, 5 th ed.

D. Van Nostrand, New York. 


\section{Distribution}

No. of

Copies

Offsite

12 DOE/Office of Scientific and Technical Information

\section{Onsite}

DOE Richland Operations Office

S. Burnam

P. Lamont

N. Brown

12 Westinghouse Hanford Company

R.B. Calmus, H5-27

R.P. Colburn, H5-27

W.C. Eaton, H5-27

J.S. Garfield, H5-49

R.L. Gibby, H5-27

S.L. Lambert, H5-27

R. Powell, H5-27 (2)

G.E. Stegen, H5-27

D.J. Washenfelder, H5-27

R.A. Watrous, H5-27

C.N. Wilson, H5-27
No. of

Copies

26 Pacific Northwest Laboratory

L.M.G. Ballou, P7-18

G.H. Bryan, P7-25

L.L. Burger, P7-25

M. Elliott

P.R. Hrma, P8-37

D.E. Larson, K9-86

E.V. Morrey, P7-19

L.R. Pederson, K2-44

J. Perez

J.L. Ryan, P7-25 (2)

G.L. Smith, P7-14

H.D. Smith, P7-14

P.A. Smith, P7-14

J.D. Vienna, P8-44

K.D. Wiemers, P7-14 (5)

Publishing Coordination

Technical Report Files (5)

Distr.1 